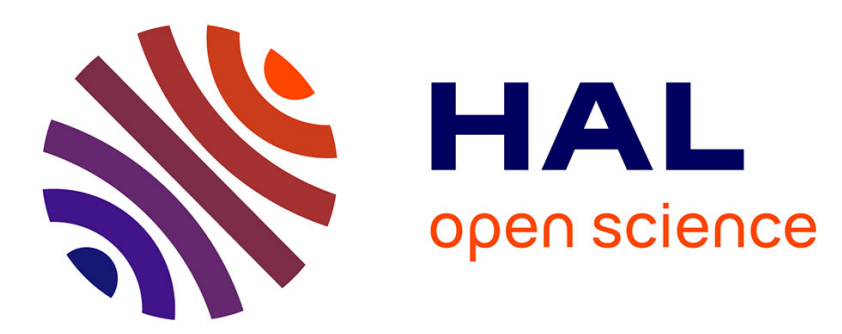

\title{
Simulation of continuous fibre reinforced thermoplastic forming using a shell finite element with transverse stress \\ Damien Soulat, Anthony Cheruet, Philippe Boisse
}

\section{- To cite this version:}

Damien Soulat, Anthony Cheruet, Philippe Boisse. Simulation of continuous fibre reinforced thermoplastic forming using a shell finite element with transverse stress. Computers \& Structures, 2006, 84 (13-14), pp.888-903. 10.1016/j.compstruc.2006.02.011 . hal-00081067

\section{HAL Id: hal-00081067 https://hal.science/hal-00081067}

Submitted on 17 Apr 2018

HAL is a multi-disciplinary open access archive for the deposit and dissemination of scientific research documents, whether they are published or not. The documents may come from teaching and research institutions in France or abroad, or from public or private research centers.
L'archive ouverte pluridisciplinaire HAL, est destinée au dépôt et à la diffusion de documents scientifiques de niveau recherche, publiés ou non, émanant des établissements d'enseignement et de recherche français ou étrangers, des laboratoires publics ou privés. 


\title{
Simulation of continuous fibre reinforced thermoplastic forming using a shell finite element with transverse stress
}

\author{
Damien Soulat $^{\mathrm{a}}$, Anthony Cheruet ${ }^{\mathrm{a}}$, Philippe Boisse ${ }^{\mathrm{b}, *}$ \\ a Laboratoire de mécanique des Systèmes et des procédés, LMSP - UMR CNRS ENSAM - Université d'Orléans, Polytech'Orléans, \\ 8 rue Léonard de Vinci, 45072 Orléans, France \\ ${ }^{\mathrm{b}}$ Laboratoire de Mécanique des Contacts et des Solides, LaMCoS, UMR CNRS 5514, INSA de Lyon, 69621 Villeurbanne Cedex, France
}

\begin{abstract}
A shell finite element with transverse stress is presented in this paper in order to simulate the forming of thermoplastic composites reinforced with continuous fibres. It is shown by an experimental work that many porosities occurs through the thickness of the composite during the heating and the forming process. Consequently the reconsolidation i.e. the porosity removing by applying a compressive stress through the thickness is a main point of the process. The presented shell finite element keeps the five degrees of freedom of the standard shell elements and adds a sixth one which is the variation in thickness. A locking phenomenon is avoided by uncoupling bending and pinching in the material law. A set of classical validation tests will prove the efficiency of this approach. Finally a forming process is simulated. It shows that the computed transverse stresses are in good agreement with porosity removing in the experiments.
\end{abstract}

Keywords: Composites; Forming; Porosities; Shell finite element; Transverse stress; Locking

\section{Introduction}

The forming processes of composite materials by stamping thin structures are complex operations involving many parameters. Geometries of the tools and of the blankholder, loading on the tools, as well as the lubrication (and many other parameters) must be optimized in order to guarantee the success of the process. In the case of composites with continuous fibers and thermoplastic matrix (CFRTP), other parameters such as the temperature, the applied pressure as well as the stacking sequence are supplementary parameters that have a main importance in the process result quality. The development of a numerical simulation software in order to determine the feasibility of a given geometry associated to a set of satisfactory parameters proves to be essential in order to reduce the development costs of a new process. This numerical simulation

\footnotetext{
* Corresponding author.

E-mail address: Philippe.Boisse@insa-lyon.fr (P. Boisse).
}

software will also allow the knowledge of the state of material in the final part. Since 15 years, the finite element method appears to be an effective framework for the simulation of the forming processes and in particular sheet metal forming $[1,2]$. In the case of the composites a numerical simulation software for the forming simulation of the thin parts will have to be able to predict the final orientation of fibers that will determine the mechanical properties of the final part. It will also have to predict wrinkling, the final thickness and the final quality of the product (presence of porosities, possible rupture of fibers). The manufacturing process of a thermoplastic composite is made at hot temperature and requires a stage of heating followed by a punch and die stamping operation. Then a phase of reconsolidation of the stack of plies consists in a transverse compression of the composite. This last stage is absolutely necessary in order to remove porosities resulting from the other steps of the process. The process simulation must be able to describe the slip between plies as well as strain in each ply and must include the essential stage of reconsolidation. 


\section{Nomenclature}

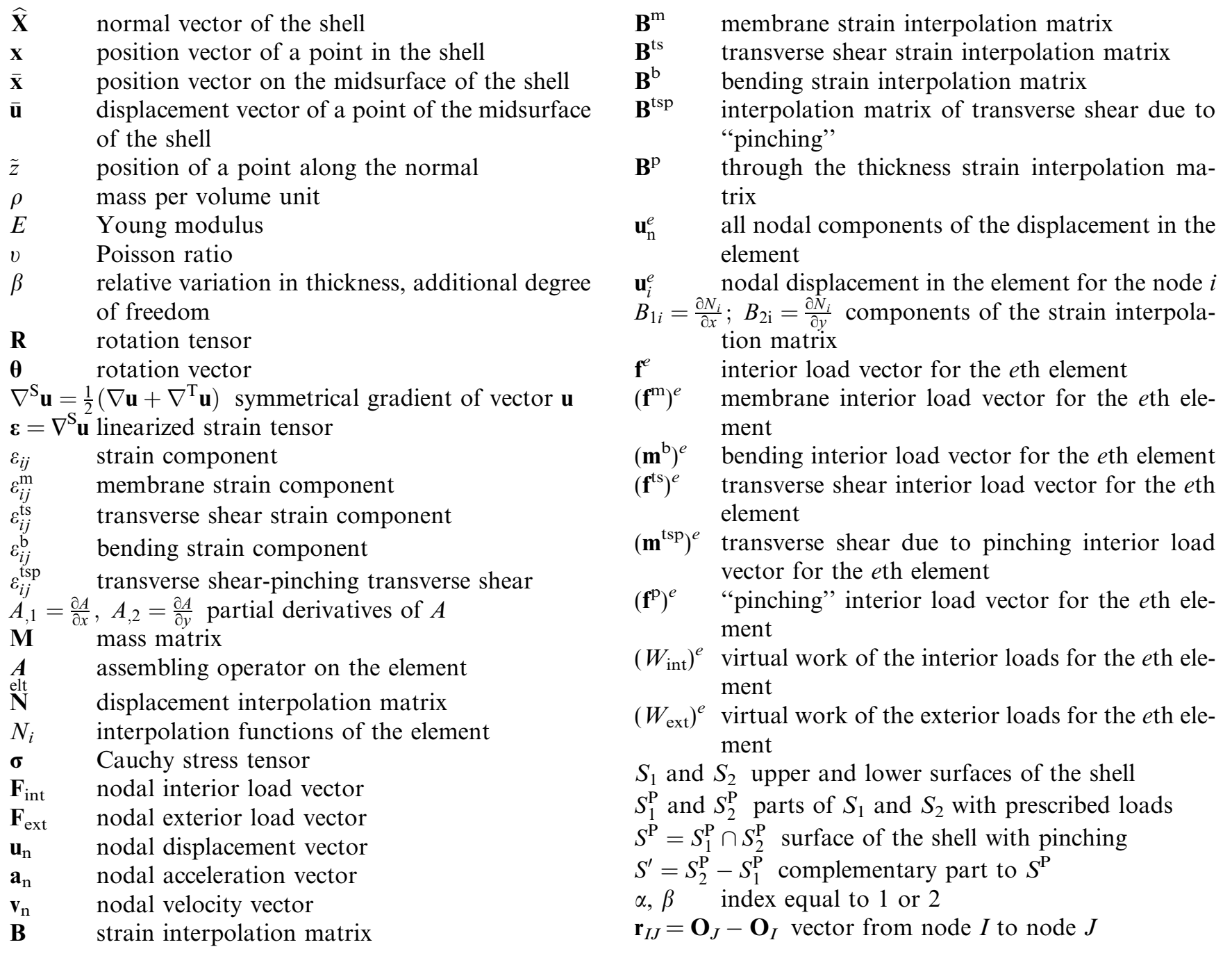

There is today a certain number of finite elements software dedicated to the simulation of forming processes and especially sheet metal forming. A majority of these software uses an explicit dynamic approach, developed at the origin for studies in fast dynamics such as crash or high speed impact. These methods are applied today successfully to sheet metal forming simulations [3]. In these finite element approaches the sheet is generally modelled by shells finite elements considering its thin geometry.

The assumption of zero normal stress component in the shell element is justified for standard sheet forming stages. Nevertheless this assumption is nor more valid when the through the thickness stress plays a main role. It is the case in CFRTP forming process in the reconsolidation stage and more generally in all the forming stage. The solution presented in this work consists in the development and use of a shell finite element with normal stress in the process simulation. Section 2 presents the manufacturing process of the CFRTP and micrographies carried out at various stages of the process. They show the importance of porosities during the process as well as the essential role of the reconsolidation stage to remove these defects. Section 3 presents the kinematics of the shell with normal stress used to simulate the forming process. The finite element implementation within an explicit approach is described in Section 4. A locking difficulty is highlighted in Section 5. It is avoided by a modification of the constitutive equations. Validation tests of the element are presented in Section 6. Finally the use of this shell finite element with normal stress for the simulation of the forming process including the reconsolidation of a part in $\mathrm{Z}$ shape will be presented in Section 7.

\section{An example where the normal stress are significant: manufacturing process of the CFRTP}

\subsection{Stages of the process}

Accounting for the difficulties related to the use of thermoset prepregs (cycle of polymerization, storage and time 


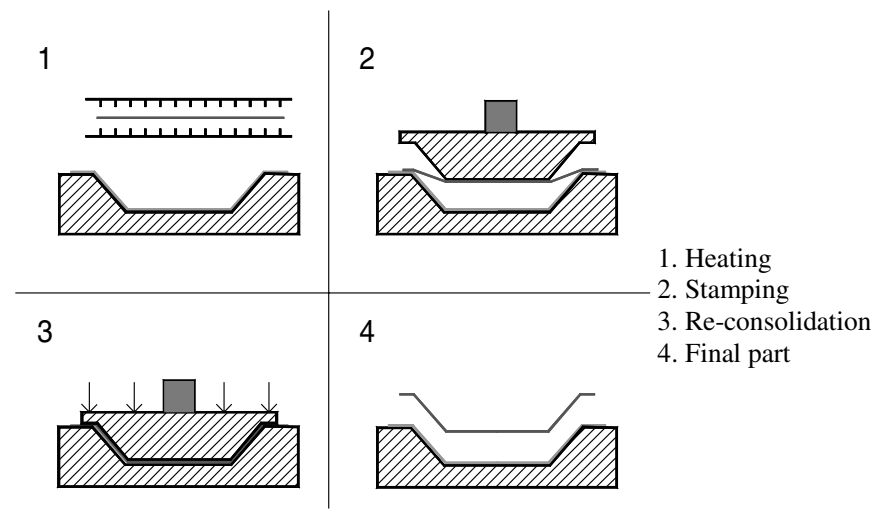

Fig. 1. Stages of the CFRTP forming process.

limitation of the products), the composites with continuous fibers and thermoplastic matrix (CFRTP) appears as a promising alternative [4-6]. Especially they are significantly present in the new civil aircrafts such as the Airbus A340600 and, A380 [7,8]. The composites with thermoplastic resin require a preliminary heating to reach a sufficiently fluid state of the resin and to make them ready for forming. After stamping and reconsolidation they are solidified by a fast cooling. The advantages compared to the thermoset matrix composites are [7]: a shorter cycle of forming, an unlimited life span of the gross products thus a greater facility of storage, a reversible aspect of the transformations that allows repairs of the structure in particular by welding. Finally, probably the more important point in the present situation is the possible recycling of the products. The stages of the CFRTP forming process are as follows: the thermoplastic plate is heated by infra-red at a temperature which is higher than the melting point of the matrix consequently the relative motion of the fibers permits deformations. This temperature is about $400{ }^{\circ} \mathrm{C}$ in the case of the PEEK matrix and $320^{\circ} \mathrm{C}$ in the case of the PPS matrix (Fig. 1.1). The plate is formed by stamping with punch and die (Fig. 1.2). After forming the part is subjected to a normal pressure between the punch and the die. This is the phase of reconsolidation (Fig. 1.3). The objective of this stage is to avoid residual porosities in the material. The objective of this paper is to present a shell finite element able to describe correctly the forming stage and the reconsolidation stage. It will be anyway shown that the compression through the thickness is present in both stages. The final part is obtained at stage 4 (Fig. 1.4).

\subsection{Experimental analysis of the reconsolidation}

These tests were carried out at the Common Research Center of EADS Suresnes $[9,10]$. The manufactured part has a $\mathrm{Z}$ shape section (Figs. 2 and 3 ). The sequence of the plies plate through the thickness is $[90,-45,0,45,0]$. The used material is APC2 with PEEK matrix and carbon fibers AS4. Each of the 10 plies has a $0.135 \mathrm{~mm}$ thickness. The laminated plate is positioned on a thermalimide film, then placed between two infrared heaters in order to bring

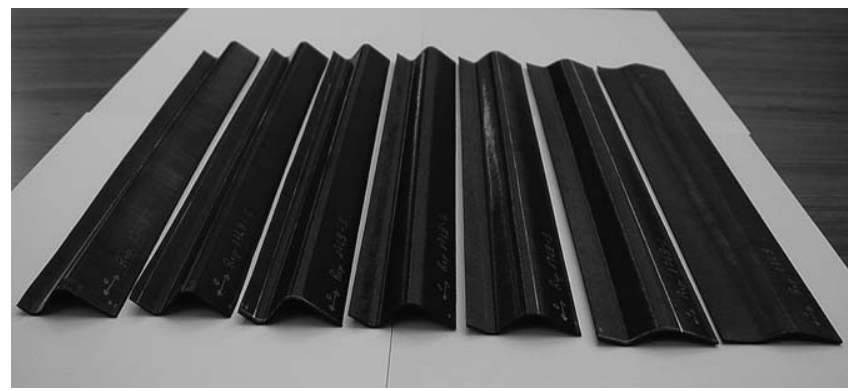

Fig. 2. Partially formed parts used for the micrography analysis.

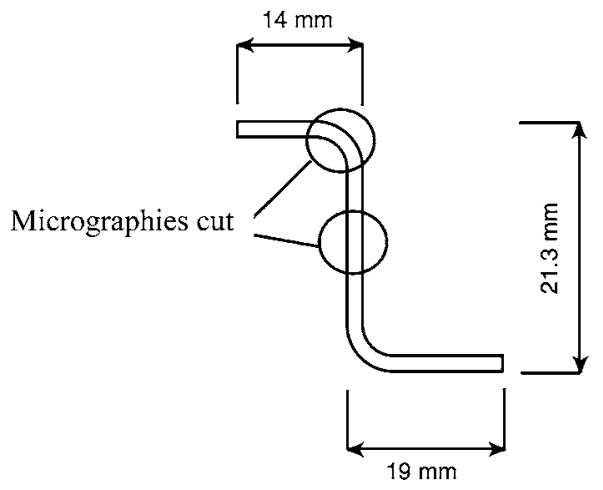

Fig. 3. Positions of the micrographies.

it up to a $400{ }^{\circ} \mathrm{C}$ temperature. It is then transferred between the punch and the die themselves heated and maintained at $250{ }^{\circ} \mathrm{C}$.

In order to obtain partially formed parts and consequently characteristics of the state of the material during forming and reconsolidation, different chocks are used in order to stop the process at different stages. Micrographies and measures have then realized on each obtained specimen (Fig. 2). These micrographies are made on a straight part of the section and in a curved part (Fig. 3).

Fig. 4 represent the state of the laminated part at the various stages of the process. Before the heating phase, the stack of plies has been preconsolidated under pressure in an autoclave and does not present any porosity (Fig. 4.1). After $1 \mathrm{~min}$ heating many porosities appear (Fig. 4.2). At the beginning of the forming cycle these defects are present in the straight parts as well in the curved parts (Fig. 4.3). At the end of the forming stage, porosities have been removed in the curved parts, but remain in the

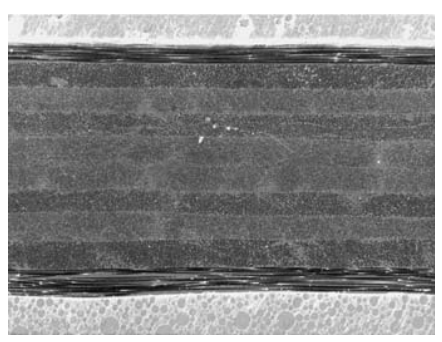

Fig. 4.1. Sample 1: Initial preconsolidated plate. 


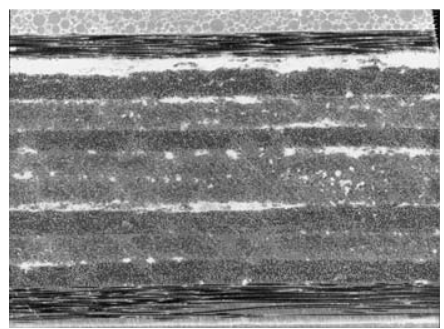

Fig. 4.2. Sample 2 after 1 min heating.
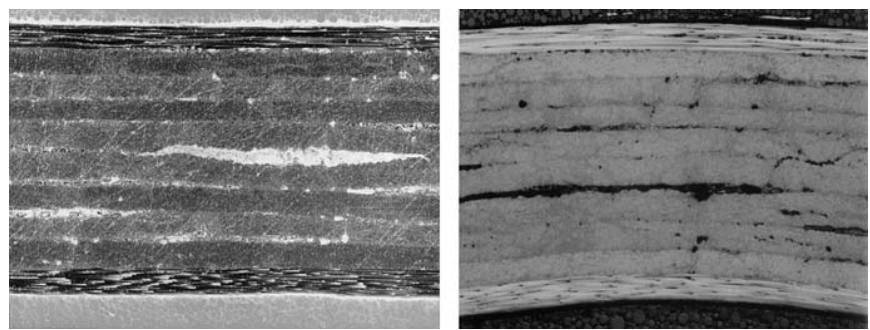

Fig. 4.3. Sample 3 at the beginning of forming (straight and curve parts).

straight one (Fig. 4.4). At the end of reconsolidation stage all the porosities are removed (Fig. 4.5).

This micrographic analysis shows the importance of the phase of reconsolidation since this application of pressure proves to be necessary to ensure the closing of porosities that are numerous. In addition the phenomenon of reconsolidation (i.e. the porosity closing) also occurs during the forming stage according to the geometry and the resulting stress states. That can be observed in the radii of curvature on the micrographies, Fig. 4.4. These experimental analyses clearly show that a prediction of the reconsolidation i.e. of the porosity removing is necessary. It must be done both in the forming stage (during which reconsolidation occurs in some places) and in the compression stage. It is important to know if this last one will be efficient. In order to obtain final parts without porosity (that is compulsory in aeronautical applications), the analysis of the transverse compaction is one of the major objectives of simulation. It is the principal objective of this paper.

\subsection{Simulation of the forming stage}

In numerical simulation of forming processes such as sheet forming, shell finite elements are generally used for the blank considering its thin geometry. Membrane finite elements are insufficient near the radii of curvature [11]. The finite element model used in the CFRTP forming stage must be able to describe the inter-ply slip which is specific to this material and is one of the principal deformation mode (Fig. 6). The laminated plate is made of several plies (10 in the example considered in Section 2.2) that slip relatively during the forming. In the approach used each ply is modeled by a layer of shells. The laminated composite is then represented by a stack of shells in contact. The inter-ply slip is managed by the introduction of viscous friction law at each interface [12]. An example, in the case of the geometry of the part with a $\mathrm{Z}$ section, is shown in Fig. 5. The computed inter-ply sliding after forming is in good agreement with the experiments (Fig. 6).

The standard construction of plate and shell models (and finite elements) is based on a null normal stress assumption. This hypothesis is generally justified in the case of thin structure where at least one of the two faces is free. Nevertheless this assumption is no more correct when the thin structures is subjected to significant compressive stresses in the thickness. (We shall use the vocabulary
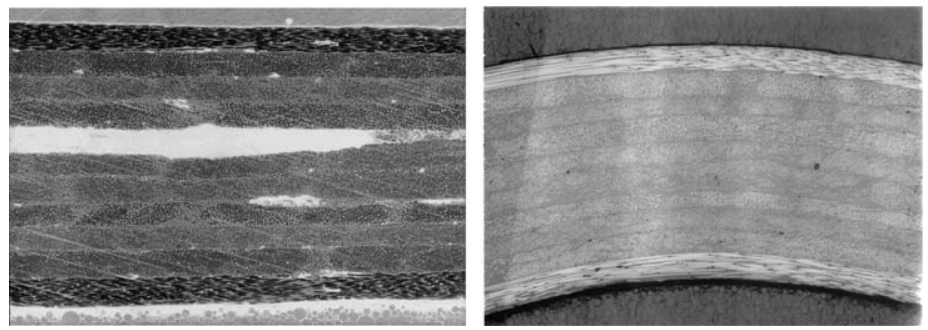

Fig. 4.4. Sample 6 at the end of forming (straight and curve parts).
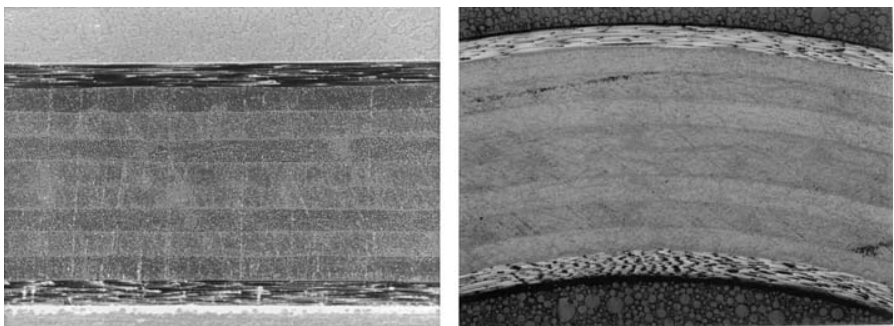

Fig. 4.5. Sample 9 at the end of the reconsolidation (straight and curve parts). 


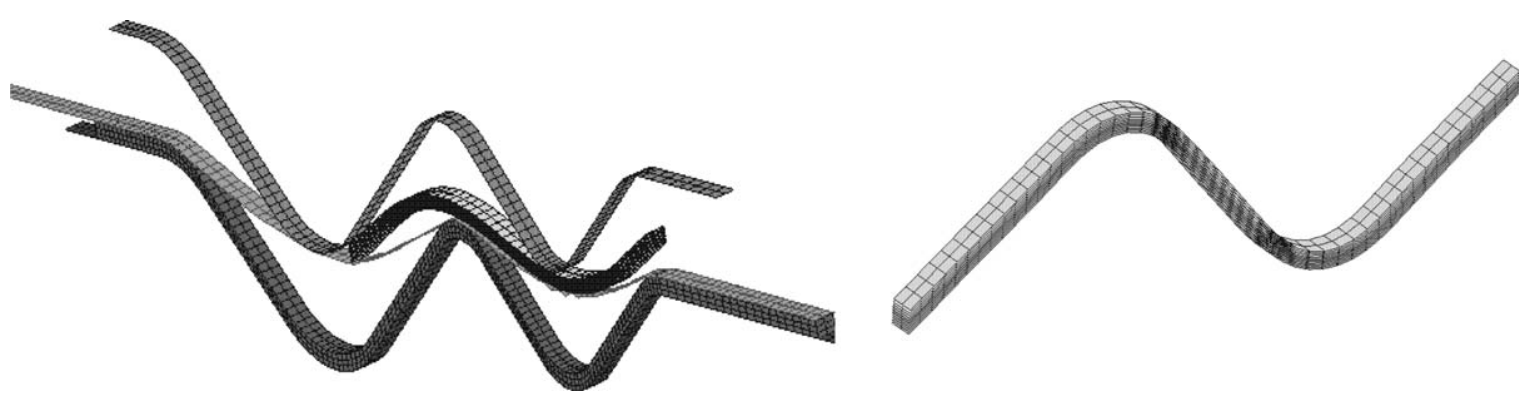

Fig. 5. Simulation of the forming stage of a laminated composite made of 10 plies.
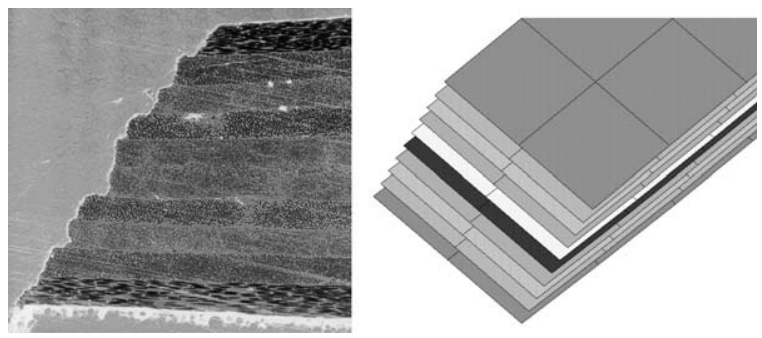

Fig. 6. Inter-ply sliding during the forming.

"pinched"). It is the case during the reconsolidation stage of the thermoplastic composites forming process (Figs. 4.1 and 4.5). In this case, it is mainly important to take the normal stress through the thickness into account. Furthermore, this is also the case in the forming stage since there are important enough transverse stresses to lead to re-consolidation in some places. In order to avoid the use of three-dimensional finite elements, a shell finite element with transverse stress (i.e. normal stress through the thickness) is developed and detailed in the next sections. This element does not use any more the assumption of null normal stress component, but computes this stress, according to the applied loads, from the through the thickness strain following a compression behaviour. The objective of the presented approach is to be as simple as possible and to keep the classical shell degrees of freedom and consequently the classical boundary conditions. It can be seen as a simplified version of the work of Simo and co-workers [15] (that employs mixed functionals).

It has been shown that the through the thickness stress component $\sigma_{33}$ is mainly important for the reconsolidation at a given temperature [9]. Furthermore the consolidation criteria proposed in the literature $[13,14]$ use the transverse stress as a main parameter. In the next section the through the thickness stress will be considered as the reconsolidation criterion for a given temperature.

\section{Shell with transverse stress kinematics}

\subsection{Shell kinematics}

The thickness at a point of the shell is defined as the distance between the upper and lower surfaces of this shell, measured along the fiber initially normal to the midsurface.

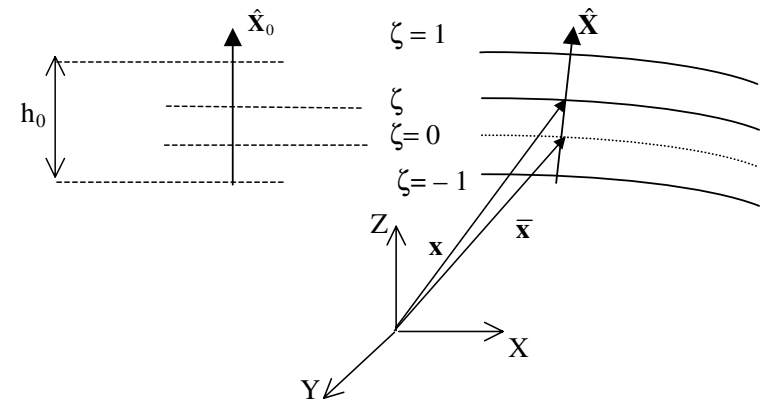

Fig. 7. Configuration (undeformed and deformed) of the shell.

This fiber defines the pseudo-normal vector $\widehat{\mathbf{X}}$. The position of a point of the shell, $\mathbf{x}$, is given by the position, $\overline{\mathbf{x}}$, of its projection onto the midsurface and its position $\tilde{z}$ along the pseudo-normal $\widehat{\mathbf{X}}$ (Fig. 7):

$\mathbf{X}=\overline{\mathbf{x}}+\tilde{z} \widehat{\mathbf{X}}$

If $\mathbf{x}^{\mathrm{t}}$ represents the position of a point and $\mathbf{x}^{0}$ its initial position, the displacement $\mathbf{u}=\mathbf{x}^{\mathrm{t}}-\mathbf{x}^{0}$, is

$\mathbf{u}=\left(\overline{\mathbf{x}}^{\mathrm{t}}-\overline{\mathbf{x}}^{0}\right)+\tilde{z}^{\mathrm{t}} \widehat{\mathbf{X}}^{\mathrm{t}}-\tilde{z}^{0} \widehat{\mathbf{X}}^{0}$

$\mathbf{u}=\overline{\mathbf{u}}+\tilde{z}^{\mathrm{t}}\left(\widehat{\mathbf{X}}^{\mathrm{t}}-\widehat{\mathbf{X}}^{0}\right)+\left(\tilde{z}^{\mathrm{t}}-\tilde{z}^{0}\right) \widehat{\mathbf{X}}^{0}$

with $\overline{\mathbf{u}}=\overline{\mathbf{x}}^{\mathrm{t}}-\overline{\mathbf{x}}^{0}$. The displacement of a point is then represented by the sum of three terms. Respectively: the displacement of the point on the midsurface, the displacement due to the pseudo-normal rotations, and the displacement due to the variation of the shell thickness.

In standard approaches, the displacement is simplified by the inextensibility assumption along the pseudo-normal, which results in the cancellation of the last term. Displacement is then given by

$\mathbf{u}=\overline{\mathbf{u}}+\tilde{z}^{\mathrm{t}}\left(\widehat{\mathbf{X}}^{\mathrm{t}}-\widehat{\mathbf{X}}^{0}\right)$

The transverse stress component is assumed to be equal to zero. That leads to a transverse strain (and a thickness variation) taking the material law into account.

\subsection{Kinematics of a shell with pinching}

Finite elements formulations with the computations of strain/stress component through the thickness have been proposed [15-18]. In the present work, the proposed finite 
element contains a single additional degree of freedom at each node which is the relative variation in thickness [19]. That permits to differentiate the displacement due to the rotation of the pseudo-normals and those due to transverse strain (or "pinching"). Displacement due to the thickness variation is not neglected any more. The through the thickness displacement of a point is denoted $\Delta h$ :

$\tilde{z}^{\mathrm{t}}=\tilde{z}^{0}+\Delta h$

From (2), one obtains:

$\mathbf{u}=\overline{\mathbf{u}}+\tilde{z}^{0}\left(\widehat{\mathbf{X}}^{\mathrm{t}}-\widehat{\mathbf{X}}^{0}\right)+\Delta h \widehat{\mathbf{X}}^{\mathrm{t}}$

Denoting $\Delta h=\tilde{z}^{\mathrm{t}}-\tilde{z}^{0}=\tilde{z}^{0} \beta$, the kinematics is

$\mathbf{u}=\overline{\mathbf{u}}+\tilde{z}^{0}\left(\widehat{\mathbf{X}}^{\mathrm{t}}-\widehat{\mathbf{X}}^{0}\right)+\tilde{z}^{0} \beta \widehat{\mathbf{X}}^{\mathrm{t}}$

If $\mathbf{R}$ is the rotation matrix which transforms the vector $\widehat{\mathbf{X}}^{0}$ into $\widehat{\mathbf{X}}^{\mathrm{t}}$, then:

$\tilde{z}^{0}\left(\widehat{\mathbf{X}}^{\mathrm{t}}-\widehat{\mathbf{X}}^{0}\right)=\tilde{z}^{0}\left(\mathbf{1}-\mathbf{R}^{\mathrm{T}}\right) \widehat{\mathbf{X}}^{\mathrm{t}}$

Under the assumption that these rotations are small between two configurations (here between two cycles of the explicit solution) it can be assumed that:

$\left(\mathbf{1}-\mathbf{R}^{\mathrm{T}}\right) \widehat{\mathbf{X}}^{\mathrm{t}}=\boldsymbol{\theta} \times \widehat{\mathbf{X}}^{\mathrm{t}}$

where $\boldsymbol{\theta}$ is the vector rotation. The kinematics with transverse strain/stress (pinching) is finally:

$\mathbf{u}=\overline{\mathbf{u}}+\boldsymbol{\theta} \times \tilde{z}^{0} \widehat{\mathbf{X}}^{\mathrm{t}}+\tilde{z}^{0} \beta \widehat{\mathbf{X}}^{\mathrm{t}}$

$\beta$ is assumed to be constant through the thickness. It is the relative variation in thickness and it is an additional degree of freedom. An interest of such a kinematics is to preserve the five traditional degree of freedom, three displacement components and two rotation components. Consequently it is possible to apply the same boundary conditions as well as the same external load. If $\beta=0$, Eq. (10) is equivalent to (4) i.e. to standard shell kinematics.

\subsection{Computation of the strain components}

In a local cartesian orthonormal frame $\left(\hat{\mathbf{e}}_{1}, \hat{\mathbf{e}}_{2}, \hat{\mathbf{e}}_{3}\right)$ with $\hat{\mathbf{e}}_{3}=\widehat{\mathbf{X}}$, the components of the small deformation tensor are

$\varepsilon_{i j}=\frac{1}{2}\left(\frac{\partial u_{i}}{\partial x_{j}}+\frac{\partial u_{j}}{\partial x_{i}}\right)$

The displacement components are those of the kinematics (10):

$\mathbf{u}=\overline{\mathbf{u}}-z \hat{\mathbf{e}}_{3} \times \boldsymbol{\theta}+z \beta \hat{\mathbf{e}}_{3}$

i.e. in $\left(\hat{\mathbf{e}}_{1}, \hat{\mathbf{e}}_{2}, \hat{\mathbf{e}}_{3}\right)$

$\left\{\begin{array}{l}u_{1}=\bar{u}_{1}+z \theta_{2} \\ u_{2}=\bar{u}_{2}-z \theta_{1} \\ u_{3}=\bar{u}_{3}+z \beta\end{array}\right.$
The different strains can be distinguished:

- Strains components of membrane and bending:

$$
\left\{\begin{array}{c}
\varepsilon_{11} \\
\varepsilon_{22} \\
2 \varepsilon_{12}
\end{array}\right\}=\left\{\begin{array}{c}
\varepsilon_{11}^{\mathrm{m}} \\
\varepsilon_{22}^{\mathrm{m}} \\
2 \varepsilon_{12}^{\mathrm{m}}
\end{array}\right\}+\left\{\begin{array}{c}
\varepsilon_{11}^{\mathrm{b}} \\
\varepsilon_{22}^{\mathrm{b}} \\
2 \varepsilon_{12}^{\mathrm{b}}
\end{array}\right\}
$$

with

$$
\left\{\begin{array}{c}
\varepsilon_{11}^{\mathrm{m}} \\
\varepsilon_{22}^{\mathrm{m}} \\
2 \varepsilon_{12}^{\mathrm{m}}
\end{array}\right\}=\left\{\begin{array}{c}
\bar{u}_{1,1} \\
\bar{u}_{2,2} \\
\bar{u}_{2,1}+\bar{u}_{1,2}
\end{array}\right\} ; \quad\left\{\begin{array}{c}
\varepsilon_{11}^{\mathrm{b}} \\
\varepsilon_{22}^{\mathrm{b}} \\
2 \varepsilon_{12}^{\mathrm{b}}
\end{array}\right\}=z\left\{\begin{array}{c}
\theta_{2,1} \\
-\theta_{1,2} \\
-\theta_{1,1}+\theta_{2,2}
\end{array}\right\}
$$

- Strain components of transverse shear and transverse shear of pinching:

$\left\{\begin{array}{l}2 \varepsilon_{13} \\ 2 \varepsilon_{23}\end{array}\right\}=\left\{\begin{array}{l}2 \varepsilon_{13}^{\mathrm{ts}} \\ 2 \varepsilon_{23}^{\mathrm{ts}}\end{array}\right\}+\left\{\begin{array}{l}2 \varepsilon_{13}^{\mathrm{tsp}} \\ 2 \varepsilon_{23}^{\mathrm{tsp}}\end{array}\right\}$

with

$$
\left\{\begin{array}{l}
2 \varepsilon_{13}^{\mathrm{ts}} \\
2 \varepsilon_{23}^{\mathrm{ts}}
\end{array}\right\}=\left\{\begin{array}{l}
\bar{u}_{3,1}+\theta_{2} \\
\bar{u}_{3,2}-\theta_{1}
\end{array}\right\} \quad\left\{\begin{array}{l}
2 \varepsilon_{13}^{\mathrm{tsp}} \\
2 \varepsilon_{23}^{\mathrm{tsp}}
\end{array}\right\}=z\left\{\begin{array}{l}
\beta_{, 1} \\
\beta_{, 2}
\end{array}\right\}
$$

- Transverse strain through the thickness (or pinching strain):

$$
\left\{\varepsilon_{33}\right\}=\beta
$$

$\varepsilon_{33}$ can result either from a load in the thickness direction (pinching), or from a coupling with the other strain components. Compared to a standard shell formulation, the transverse shear components are modified. The through the thickness stress component is not null but obtained from the strain state and the constitutive equations.

\section{Shell with transverse stress finite element}

\subsection{Development in an explicit dynamic approach}

The present work was completed by developing specific modules [9] of the Pam Form software [20]. This software is based on an explicit dynamic finite element approach. The discrete form of the dynamics equation at the time $t_{i}$ leads to

$\mathbf{M a}_{\mathrm{n}}^{(i)}+\mathbf{F}_{\mathrm{int}}\left(\mathbf{u}_{\mathrm{n}}^{(i)}\right)=\mathbf{F}_{\mathrm{ext}}^{(i)}$

where $\mathbf{M}$ is the mass matrix $\mathbf{F}_{\text {int }}$ and $\mathbf{F}_{\text {ext }}$ are respectively interior and exterior nodal load vectors such as

$\mathbf{M}=\underset{\text { elt }}{\boldsymbol{A}} \int_{\Omega_{\mathrm{e}}} \mathbf{N}^{\mathrm{T}} \mathbf{N} \rho \mathrm{d} V$

$\mathbf{F}_{\mathrm{int}}=\underset{\text { elt }}{\boldsymbol{A}} \int_{\Omega_{\mathrm{e}}} \mathbf{B}^{\mathrm{T}} \boldsymbol{\sigma} \mathrm{d} V$

$\mathbf{F}_{\text {ext }}=\underset{\text { elt }}{\boldsymbol{A}} \int_{\Omega_{\mathrm{e}}} \mathbf{N}^{\mathrm{T}} \mathbf{f} \mathrm{d} V+\underset{\text { elt }}{\boldsymbol{A}} \int_{\Gamma_{\mathrm{e}}} \mathbf{N}^{\mathrm{T}} \mathbf{t} \mathrm{d} S$

$\mathbf{N}$ and $\mathbf{B}$ are respectively the displacement and strain interpolation matrix:

$\mathbf{u}=\mathbf{N} \mathbf{u}_{\mathrm{n}}^{e} \quad$ and $\quad \nabla^{\mathrm{S}} \boldsymbol{\delta} \mathbf{u}=\boldsymbol{\delta} \boldsymbol{\varepsilon}=\mathbf{B}\left(\boldsymbol{\delta} \mathbf{u}_{\mathrm{n}}^{e}\right)$ 
or

$\nabla^{\mathrm{S}} \mathbf{u}=\boldsymbol{\varepsilon}=\mathbf{B} \mathbf{u}_{\mathrm{n}}^{e}$

where $\varepsilon$ is the small strain tensor. The central differences scheme is used to compute explicitly the displacements and velocities at each time step. The nodal accelerations are computed at time $t_{i}$ from (19) considering a diagonal form of $\mathbf{M}$ :

$\mathbf{a}_{\mathrm{n}}^{(i)}=\mathbf{M}^{-1}\left(\mathbf{F}_{\mathrm{ext}}^{(i)}-\mathbf{F}_{\text {int }}\left(\mathbf{u}_{\mathrm{n}}^{(i)}\right)\right)$

Then the nodal velocities and displacements are computed:

$\mathbf{v}_{\mathrm{n}}^{(i+1 / 2)}=\mathbf{v}_{\mathrm{n}}^{(i-1 / 2)}+\Delta t^{(i)} \mathbf{a}_{\mathrm{n}}^{(i)}$

$\mathbf{u}_{\mathrm{n}}^{(i+1)}=\mathbf{u}_{\mathrm{n}}^{(i)}+\Delta t^{(i+1 / 2)} \mathbf{v}_{\mathrm{n}}^{(i+1 / 2)}$

\subsection{Finite element interpolation}

A four node shell finite element based on the approach presented at Section 3, is implemented (Fig. 8). The interpolation functions are bilinear and a reduced integration is made at the center of the element. A local frame $\left(\hat{\mathbf{e}}_{1}, \hat{\mathbf{e}}_{2}, \hat{\mathbf{e}}_{3}\right)$ is defined on each element by the followings steps [21]: first, the local vector $\hat{\mathbf{e}}_{3}$ is assumed to be the normal to the vector $\mathbf{r}_{13}$ and $\mathbf{r}_{24}$ (Fig. 8 and Nomenclature). The components of $\hat{\mathbf{e}}_{3}$ are then computed, from the position of the nodes, by

$\hat{\mathbf{e}}_{3}=\frac{\mathbf{r}_{13} \times \mathbf{r}_{24}}{\left\|\mathbf{r}_{13} \times \mathbf{r}_{24}\right\|}$

The vector $\hat{\mathbf{e}}_{1}$ lies in the plane parallel to the direction of $\hat{\mathbf{e}}_{3}$ containing nodes 1 and 2 :

$\hat{\mathbf{e}}_{1}=\frac{\mathbf{r}_{12}-\left(\mathbf{r}_{12} \cdot \hat{\mathbf{e}}_{3}\right) \hat{\mathbf{e}}_{3}}{\left\|\mathbf{r}_{12}-\left(\mathbf{r}_{12} \cdot \hat{\mathbf{e}}_{3}\right) \hat{\mathbf{e}}_{3}\right\|}$

Vector $\hat{\mathbf{e}}_{2}$ is obtained by

$\hat{\mathbf{e}}_{2}=\hat{\mathbf{e}}_{3} \times \hat{\mathbf{e}}_{1}$

The position of a point of the midsurface of the shell is interpolated from the nodal positions using the standard bilinear functions:

$$
\begin{aligned}
& \left\{\begin{array}{c}
\bar{x} \\
\bar{y} \\
\bar{z}
\end{array}\right\}=N_{i}(\xi, \eta)\left\{\begin{array}{c}
x_{i} \\
y_{i} \\
z_{i}
\end{array}\right\} \\
& N_{1}=\frac{1}{4}(1-\xi)(1-\eta) ; \quad N_{2}=\frac{1}{4}(1+\xi)(1-\eta) \\
& N_{3}=\frac{1}{4}(1+\xi)(1+\eta) ; \quad N_{4}=\frac{1}{4}(1-\xi)(1+\eta)
\end{aligned}
$$

The displacements of the points of midsurface, the rotations as well as the pinching degrees of freedom $\beta$ are interpolated with the same interpolation functions:

$\left\{\begin{array}{l}\bar{u}=N_{i} u_{i} \\ \theta=N_{i} \theta_{i} \\ \beta=N_{i} \beta_{i}\end{array}\right.$

The vector $\mathbf{u}_{\mathrm{n}}^{e}$ of the degrees of freedom of the element is $(i=1-4)$ :

$$
\begin{aligned}
& \left\{\mathbf{u}_{\mathrm{n}}^{e}\right\}^{\mathrm{T}}=\left\{\left\{\mathbf{u}_{1}^{e}\right\}^{\mathrm{T}}\left\{\mathbf{u}_{2}^{e}\right\}^{\mathrm{T}}\left\{\mathbf{u}_{3}^{e}\right\}^{\mathrm{T}}\left\{\mathbf{u}_{4}^{e}\right\}^{\mathrm{T}}\right\}, \\
& \left\{\mathbf{u}_{i}^{e}\right\}^{\mathrm{T}}=\left[\begin{array}{llllll}
u_{1 i} & u_{2 i} & u_{3 i} & \theta_{1 i} & \theta_{2 i} & \beta_{i}
\end{array}\right]
\end{aligned}
$$

As it is classical in explicit approach, in a goal of numerical effectiveness and to avoid transverse shear locking, a reduced integration is made, i.e. a single integration point (located at $\xi=0$ and $\eta=0$ ) and hour glass control in order to avoid spurious energy modes. The different strains defined in (14)-(18) are interpolated in function of nodal displacements:

$$
\begin{aligned}
& \left\{\begin{array}{c}
\varepsilon_{11} \\
\varepsilon_{22} \\
2 \varepsilon_{12}
\end{array}\right\}=\left[\mathbf{B}_{i}^{\mathrm{m}}\right]\left\{\mathbf{u}_{i}^{e}\right\}+\left[\mathbf{B}_{i}^{\mathrm{b}}\right]\left\{\mathbf{u}_{i}^{e}\right\} \\
& \left\{\begin{array}{c}
2 \varepsilon_{13} \\
2 \varepsilon_{23}
\end{array}\right\}=\left[\mathbf{B}_{i}^{\mathrm{ts}}\right]\left\{\mathbf{u}_{i}^{e}\right\}+\left[\mathbf{B}_{i}^{\mathrm{tsp}}\right]\left\{\mathbf{u}_{i}^{e}\right\} \\
& \left\{\varepsilon_{33}\right\}=\left[\mathbf{B}_{i}^{\mathrm{p}}\right]\left\{\mathbf{u}_{i}^{e}\right\}
\end{aligned}
$$
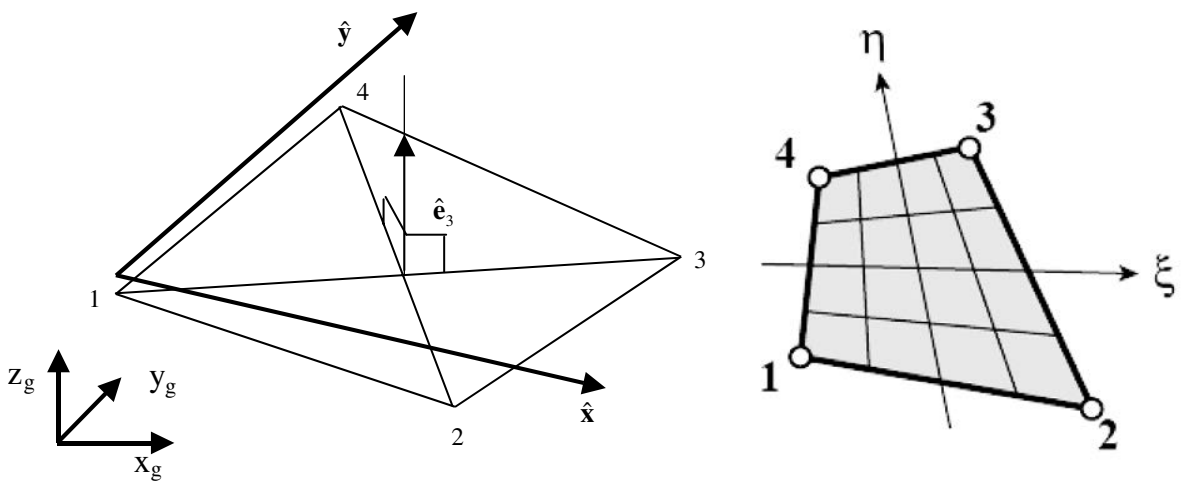

Fig. 8. Local frame for the four-node element and reference element. 
With the following strain interpolation matrix:

$$
\begin{aligned}
& {\left[\mathbf{B}_{i}^{\mathrm{m}}\right]=\left[\begin{array}{cccccc}
B_{1 i} & 0 & 0 & 0 & 0 & 0 \\
0 & B_{2 i} & 0 & 0 & 0 & 0 \\
B_{2 i} & B_{1 i} & 0 & 0 & 0 & 0
\end{array}\right] ;} \\
& {\left[\mathbf{B}_{i}^{\mathrm{b}}\right]=\left[\begin{array}{cccccc}
0 & 0 & 0 & 0 & z B_{1 i} & 0 \\
0 & 0 & 0 & -z B_{2 i} & 0 & 0 \\
0 & 0 & 0 & -z B_{1 i} & z B_{2 i} & 0
\end{array}\right]} \\
& {\left[\mathbf{B}_{i}^{\mathrm{ts}}\right]=\left[\begin{array}{llllll}
0 & 0 & B_{1 i} & 0 & N_{i} & 0 \\
0 & 0 & B_{2 i} & -N_{i} & 0 & 0
\end{array}\right] ;} \\
& {\left[\mathbf{B}_{i}^{\mathrm{tsp}}\right]=\left[\begin{array}{llllll}
0 & 0 & 0 & 0 & 0 & z B_{1 i} \\
0 & 0 & 0 & 0 & 0 & z B_{2 i}
\end{array}\right]} \\
& {\left[\mathbf{B}_{i}^{\mathrm{p}}\right]=\left[\begin{array}{llllll}
0 & 0 & 0 & 0 & 0 & N_{i}
\end{array}\right]}
\end{aligned}
$$

where

$B_{1 i}=\frac{\partial N_{i}}{\partial x} ; \quad B_{2 i}=\frac{\partial N_{i}}{\partial y}$

\subsection{Computation of the interior nodal loads}

According to Eqs. (19)-(22), the virtual work of the elementary interior load is

$\left(W_{\text {int }}\right)^{e}=\int_{V^{e}} \boldsymbol{\delta} \boldsymbol{\varepsilon}^{\mathrm{T}} \boldsymbol{\sigma} \mathrm{d} V=\int_{V^{e}} \boldsymbol{\delta} \mathbf{u}_{\mathrm{n}}^{e}\left(\mathbf{B}^{\mathrm{T}} \boldsymbol{\sigma}\right) \mathrm{d} V$

i.e.

$\left(W_{\text {int }}\right)^{e}=\delta u_{i}^{m} f_{i}+\delta \theta_{i} m_{i}+\delta \beta_{i} p_{i}$

where $f_{i}, m_{i}$ and $p_{i}$ are the nodal interiors loads and moments associated to the degrees of freedom of the element. After computing the stress components, these elementary nodal interior load are obtained by $\int_{S^{e}} \mathbf{B}^{\mathrm{T}} \mathbf{f} \mathrm{d} S$. This computation is carried out in two stages:

(a) Computation of the elementary stress resultants $\mathbf{f}$ at the single gauss point at the center of the midsurface by integration through the thickness [22]:

$f_{\alpha \beta}^{e}=\int_{-\frac{h}{2}}^{\frac{h}{2}} \sigma_{\alpha \beta} \mathrm{d} z ; \quad$ and $\quad m_{\alpha \beta}^{e}=\int_{-\frac{h}{2}}^{\frac{h}{2}} z \sigma_{\alpha \beta} \mathrm{d} z$

That gives the elementary resultant stress tensor:

- of membrane:

$$
\mathbf{f}^{\mathrm{m}}=f_{11} \hat{\mathbf{e}}_{1} \otimes \hat{\mathbf{e}}_{1}+f_{22} \hat{\mathbf{e}}_{2} \otimes \hat{\mathbf{e}}_{2}+f_{12}\left(\hat{\mathbf{e}}_{1} \otimes \hat{\mathbf{e}}_{2}+\hat{\mathbf{e}}_{2} \otimes \hat{\mathbf{e}}_{1}\right)
$$

- of bending:

$$
\mathbf{m}^{\mathrm{b}}=m_{11} \hat{\mathbf{e}}_{1} \otimes \hat{\mathbf{e}}_{1}+m_{22} \hat{\mathbf{e}}_{2} \otimes \hat{\mathbf{e}}_{2}+m_{12}\left(\hat{\mathbf{e}}_{1} \otimes \hat{\mathbf{e}}_{2}+\hat{\mathbf{e}}_{2} \otimes \hat{\mathbf{e}}_{1}\right)
$$

- of transverse shear:

$$
\mathbf{f}^{\mathrm{ts}}=f_{13}\left(\hat{\mathbf{e}}_{1} \otimes \hat{\mathbf{e}}_{3}+\hat{\mathbf{e}}_{3} \otimes \hat{\mathbf{e}}_{1}\right)+f_{23}\left(\hat{\mathbf{e}}_{2} \otimes \hat{\mathbf{e}}_{3}+\hat{\mathbf{e}}_{3} \otimes \hat{\mathbf{e}}_{2}\right)
$$

- of transverse shear-pinching:

$$
\mathbf{m}^{\text {tsp }}=m p_{13}\left(\hat{\mathbf{e}}_{1} \otimes \hat{\mathbf{e}}_{3}+\hat{\mathbf{e}}_{3} \otimes \hat{\mathbf{e}}_{1}\right)+m p_{23}\left(\hat{\mathbf{e}}_{2} \otimes \hat{\mathbf{e}}_{3}+\hat{\mathbf{e}}_{3} \otimes \hat{\mathbf{e}}_{2}\right)
$$

- of pinching:

$$
\mathbf{f}^{\mathrm{p}}=f p_{33} \hat{\mathbf{e}}_{3} \otimes \hat{\mathbf{e}}_{3}
$$

(b) Computation of the elementary interior nodal load vector:

$$
\mathbf{F}_{\text {int }}^{e}=\int_{S^{e}} \mathbf{B}^{\mathrm{T}} \mathbf{f} \mathrm{d} S
$$

where $S_{e}$ denotes the element surface. This vector has, for each node, six components whose five first are of same nature that those of the formulation of a standard shell element. The addition of a pinching degree of freedom $\beta$ adds only one interior load component. For node $i$, accounting for the reduced integration, the six components of $\mathbf{F}_{\text {int }}^{e}$ related to node $i$ are

$f_{1 \mathrm{I}}^{e}=S_{e}\left(B_{1 \mathrm{I}} f_{11}+B_{2 \mathrm{I}} f_{12}\right) ; \quad f_{2 \mathrm{I}}^{e}=S_{e}\left(B_{2 \mathrm{I}} f_{22}+B_{1 \mathrm{I}} f_{12}\right)$

$f_{3 \mathrm{I}}^{e}=S_{e} \lambda\left(B_{1 \mathrm{I}} f_{13}+B_{2 \mathrm{I}} f_{23}\right)$

$m_{1 \mathrm{I}}^{e}=S_{e}\left(B_{2 \mathrm{I}} m_{22}+B_{1 \mathrm{II}} m_{12}-\frac{1}{4} \lambda f_{23}\right) ;$

$m_{2 \mathrm{I}}^{e}=-S_{e}\left(B_{1 \mathrm{I}} m_{11}+B_{2 \mathrm{I}} m_{12}-\frac{1}{4} \lambda f_{13}\right)$

$m_{3 \mathrm{I}}^{e}=S_{e}\left(B_{2 \mathrm{I}} m p_{23}+B_{1 \mathrm{I}} m p_{13}+\frac{1}{4} f p_{33}\right)$

where $\lambda$ is the shear factor. The physical interpretation of these elementary nodal load components have been given in [22], in the case of a shell element with seven parameters. Table 1 compares the dimensions of strain components, and nodal loads for the formulation of the presented four node shell element with pinching to a standard shell approach.

\subsection{Computation of the external nodal load}

The external virtual work includes the work of an external load on the degree of freedom of pinching. On an element:

$$
\left(W_{\text {ext }}\right)^{e}=\int_{V_{e}} \boldsymbol{\delta} \boldsymbol{\varepsilon}^{\mathrm{T}} \mathbf{f}_{\text {ext }} \mathrm{d} V=\int_{V_{e}}\left(\delta u_{i}\right)^{\mathrm{T}}\left(f_{i}^{\text {ext }}\right) \mathrm{d} V
$$

Table 1

Matrix and vectors sizes

\begin{tabular}{lll}
\hline & Strain & Nodal load vector \\
\hline Size of the matrix and vector for a standard shell (5 d.o.f./node) & $\boldsymbol{\varepsilon}^{e}=\mathbf{B} \mathbf{u}_{\mathrm{n}}^{e}$ & $\mathbf{f}^{e}=\int_{S^{e}} \mathbf{B}^{\mathrm{T}} \mathbf{f} \mathrm{d} S$ \\
Size of the matrix and vector for a shell with pinching (6 d.o.f./node) & $(8 \times 1)=(8 \times 20)(20 \times 1)$ & $(20 \times 1)=(20 \times 8)(8 \times 1)$ \\
\hline
\end{tabular}



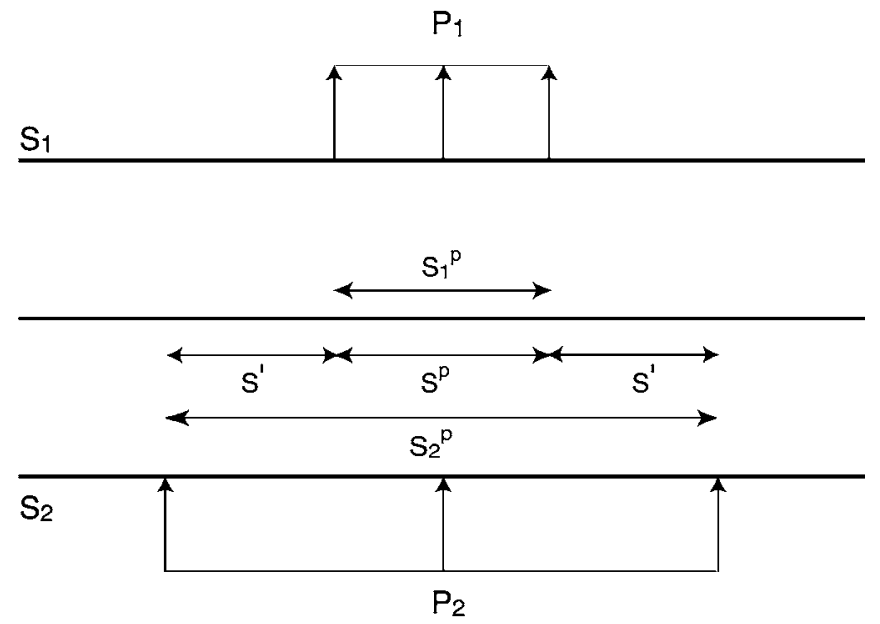

Fig. 9. Pressures on upper and lower surfaces of the shell.

with

$\left(\mathbf{f}_{i}^{\text {ext }}\right)^{\mathrm{T}}=\left[\begin{array}{llllll}f_{x i}^{\text {ext }} & f_{y i}^{\text {ext }} & f_{z i}^{\text {ext }} & m_{x i}^{\text {ext }} & m_{y i}^{\text {ext }} & f_{p i}^{\text {ext }}\end{array}\right]$

$\left(\boldsymbol{\delta \mathbf { u } _ { i }}\right)^{\mathrm{T}}=\left[\begin{array}{llllll}\delta u_{x i} & \delta u_{y i} & \delta u_{z i} & \delta \theta_{x i} & \delta \theta_{y i} & \delta \beta_{i}\end{array}\right]$

Compared to the standard formulation, only the transverse load $f p_{i}^{\text {ext }}$ must be defined. According to the notation defined in the nomenclature and in Fig. 9, in case of surface load on $S_{1}^{\mathrm{P}}$ and $S_{2}^{\mathrm{P}}$ (Fig. 9):

$$
\begin{aligned}
\left(W_{\text {ext }}\right)^{e}= & \int_{S_{1}^{\mathrm{P}}} p_{1}\left(\delta u_{z}+\delta u_{p}^{+}\right) \mathrm{d} S_{1}^{P}+\int_{S_{2}^{\mathrm{P}}} p_{2}\left(\delta u_{z}+\delta u_{p}^{-}\right) \mathrm{d} S_{2}^{P} \\
\left(W_{\text {ext }}\right)^{e}= & \int_{S^{\mathrm{P}}}\left(p_{1}+p_{2}\right)\left(\delta u_{z}\right) \mathrm{d} S^{P}+\int_{S^{\mathrm{P}}}\left(p_{1}-p_{2}\right) \frac{h}{2}(\delta \beta) \mathrm{d} S^{P} \\
& +\int_{S^{\prime}} p_{2}\left(\delta u_{z}+\delta u_{p}\left(-\frac{h}{2}\right)\right) \mathrm{d} S^{\prime}
\end{aligned}
$$

The first part of (53) corresponds to the work of the external load on the midsurface, the second corresponds to the work of the pinching load. For the case $S_{1}^{\mathrm{P}}=S_{2}^{\mathrm{P}}$ :

- If $p_{1}=p_{2}$ the shell moves transversely without pinching.

- If $p_{1}=-p_{2}$ the shell is only subjected to 'pure' pinching. This feature is not taken into account in standard shells. This loading is typical of the reconsolidation stage of the CFRTP forming.

- If $\left|p_{1}\right| \neq\left|p_{2}\right|$ the shell moves transversely and is also pinched. This loading is typical of the CFRTP forming stage.

Within the finite element approach (53) leads to the following exterior nodal pinching load:

$$
\begin{aligned}
\left(W_{\mathrm{ext}}^{\mathrm{p}}\right)^{e} & =\boldsymbol{\delta} \boldsymbol{\beta}_{i}^{e^{\mathrm{T}}} \int_{S^{\mathrm{P}}} \mathbf{N}^{\mathrm{T}}\left(p_{1}-p_{2}\right) \frac{h}{2} \mathrm{~d} S^{P}+\boldsymbol{\delta} \boldsymbol{\beta}_{i}^{e^{\mathrm{T}}} \int_{S^{\prime}} \mathbf{N}^{\mathrm{T}} p_{2} \frac{h}{2} \mathrm{~d} S^{\prime} \\
& =\boldsymbol{\delta} \boldsymbol{\beta}_{i}^{e^{\mathrm{T}}} \mathbf{F}_{i}^{\mathrm{p}}
\end{aligned}
$$

\section{Pinching locking}

\subsection{Locking of a clamped plate}

The shell element described above leads to a locking phenomenon due to addition of the pinching degree of freedom if the standard material law is used.

This is shown here on a simple example. A cantilever plate length $L=0.1 \mathrm{~m}$, width $l=0.01 \mathrm{~m}$ is clamped on an end and subjected to a load on the free end (Fig. 10). Three thickness values are used: $h=0.01,0.001,0.0001 \mathrm{~m}$, i.e. length thickness ratio equal to 10,100 and 1000 . The material is assumed to be isotropic and elastic: $E=10^{7} \mathrm{~Pa}$, $v=0.3$. The applied load depends on the thickness in order to obtain the same transverse displacement in the three cases: $F=1.5 E+06 \times h^{3}$. The mesh used is composed of $20 \times 2$ elements. The maximum transverse displacement obtained by the shell with pinching element is compared in Table 2 with the theoretical transverse displacement. This theoretical value is also those given accurately by a standard shell element. This test shows a locking phenomenon for the shell with pinching. The error is more important as the thickness decreases. In this test the complete three-dimensional material law is used.

\subsection{The reason for locking}

In linear elasticity the normal stress component is

$\sigma_{33}=C_{33 \alpha \beta} \varepsilon_{\alpha \beta}+C_{3333} \varepsilon_{33}$

i.e. considering the membrane and bending part of the strains:

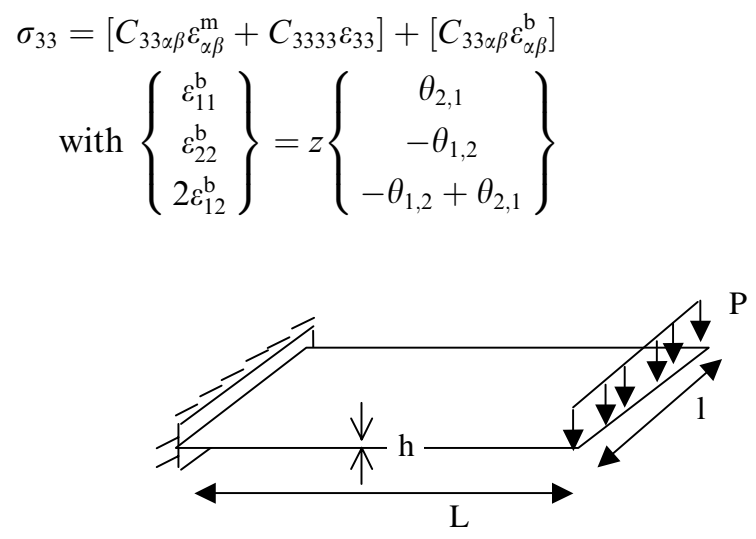

Fig. 10. Cantilever plate test.

Table 2

Effectiveness of bending-pinching uncoupling

\begin{tabular}{llll}
\hline Transverse displacement $(\mathrm{m})$ & \\
\hline $\begin{array}{l}\text { Thickness } \\
(\mathrm{m})\end{array}$ & $\begin{array}{l}\text { Standard } \\
\text { shell } \\
\text { element }\end{array}$ & $\begin{array}{l}\text { Shell with pinching } \\
\text { element with } \\
\text { bending uncoupling }\end{array}$ & $\begin{array}{l}\text { Shell with pinching } \\
\text { element with }\end{array}$ \\
\hline 0.01 & -0.044 & -0.044 & 3D behavior \\
\hline 0.001 & -0.044 & -0.044 & -0.038 \\
0.0001 & -0.044 & -0.044 & -0.037 \\
\hline
\end{tabular}


If this structure is in a bending state (without pinching, that is the case for the cantilever plate of Fig. 10), and if the thickness is small, the through the thickness stress must be equal to zero. However the bending term of (56) leads to a parasitic normal stress when $z$ is different from zero. This is the reason for the "pinching" locking. Accounting for the material law, all the stress and strain components are perturbed by the parasitic normal stress.

The first possibility to avoid this locking phenomenon is to uncouple bending and pinching strains by a modification of the three-dimensional behaviour law $[15,23,24]$. That is the case in standard shell approach where the transverse strain is obtained from $\sigma_{33}=0$. This uncoupling permits to calculate the bending stresses by a two-dimensional law assuming that bending never leads to transverse stress. Consequently the parasitic stresses highlighted above are no more calculated. This approach is simple. To neglect the bending-pinching coupling is not a strong assumption, consequently this approach is used in the presented element.

In order to cancel the through the thickness stress in (56), an alternative to this condensation of the bending behaviour consists in the introduction of a seventh degree of freedom that permits to have a linear through the thickness strain and consequently obtain the linear and constant parts of $\sigma_{33}$. That has been done by the use of a quadratic term in the transverse displacement $[25,26]$ or by an increase of the strain field degree in a mixed approach [16].

In this work, the first approach is used and the constitutive equation is modified. In the case of an isotropic linear elastic material, for which the terms of behaviour matrix are

$$
\begin{aligned}
& C_{1111}=C_{2222}=C_{3333}=\frac{E(1-v)}{(1+v)(1-2 v)} \\
& C_{1122}=C_{1133}=C_{2233}=\frac{E v}{(1+v)(1-2 v)} \\
& C_{1212}=C_{1313}=C_{2323}=\frac{E}{2(1+v)}
\end{aligned}
$$

The modification of the material law that have been presented above gives:

$$
\begin{aligned}
&\left\{\begin{array}{l}
\sigma_{11} \\
\sigma_{22} \\
\sigma_{12} \\
\sigma_{33}
\end{array}\right\}= {\left[\begin{array}{cccc}
C_{1111} & C_{1122} & 0 & C_{1133} \\
C_{1122} & C_{2222} & 0 & C_{2233} \\
0 & 0 & C_{1212} & 0 \\
C_{1133} & C_{2233} & 0 & C_{3333}
\end{array}\right]\left\{\begin{array}{l}
\varepsilon_{11}^{\mathrm{m}} \\
\varepsilon_{22}^{\mathrm{m}} \\
\varepsilon_{12}^{\mathrm{m}} \\
\varepsilon_{33}
\end{array}\right\} } \\
&+\left[\begin{array}{cccc}
C_{1111}^{*} & C_{1122}^{*} & 0 & 0 \\
C_{1122}^{*} & C_{1111}^{*} & 0 & 0 \\
0 & 0 & C_{1212} & 0 \\
0 & 0 & 0 & 0
\end{array}\right]\left\{\begin{array}{c}
\varepsilon_{11}^{\mathrm{b}} \\
\varepsilon_{22}^{\mathrm{b}} \\
\varepsilon_{12}^{\mathrm{b}} \\
0
\end{array}\right\} \\
&\left\{\begin{array}{l}
\sigma_{13} \\
\sigma_{23}
\end{array}\right\}=\left[\begin{array}{ccc}
C_{1313} & 0 \\
0 & C_{2323}
\end{array}\right]\left\{\begin{array}{c}
\varepsilon_{13}^{\text {ts }}+\varepsilon_{13}^{\text {tsp }} \\
\varepsilon_{23}^{\text {ts }}+\varepsilon_{23}^{\text {tsp }}
\end{array}\right\}
\end{aligned}
$$

with

$$
\begin{aligned}
& C_{1111}^{*}=C_{2222}^{*}=\frac{(1+v)(1-2 v)}{\left(1-v^{2}\right)(1-v)} * C_{1111} \\
& C_{1122}^{*}=\frac{(1+v)(1-2 v)}{\left(1-v^{2}\right)} * C_{1122}
\end{aligned}
$$

Table 2 shows the results obtained on the bending test previously presented in Section 5.1 with the element with pinching including the above behavior law with bending uncoupling. It can be seen that locking disappears.

\section{Validation tests}

\subsection{Crushing under pressure}

The coupling between membrane and pinching strain components are highlighted for the presented element. Computations carried out with the presented shell element are compared with results given by a three-dimensional model. The geometry and the boundary conditions of the tests discussed in Sections 6.1 and 6.2 are specified Fig. 11. The data are $E=120 \mathrm{E}+09 \mathrm{~Pa}, v=0.3, L=50 \mathrm{~mm}$, thickness $h=$ $4 \mathrm{~mm}$.

First a constant normal pressure is applied to upper and lower external surfaces. The initial pressure is equal to zero, then it linearly reaches $1 \cdot \mathrm{E}+10 \mathrm{~Pa}$ to come back to a zero value. Meshes of the shell and three-dimensional models are shown in Fig. 12. The through the thickness stress component, the displacement of the node and the thickness are compared with those obtained with the three-dimensional model. The displacements, transverse strain and thickness results obtained by the shell with pinching are similar to those of the three-dimensional model (Figs. 13 and 14). The through the thickness stress is constant and equal to the prescribed pressure value. The test is then realized with a pressure that is depending linearly on the $x$-coordinate (Fig. 15). Fig. 16.1 and 2 show that the through the thickness stress fields and thickness fields obtained with the 3D computation and the presented shell element are in good agreement.

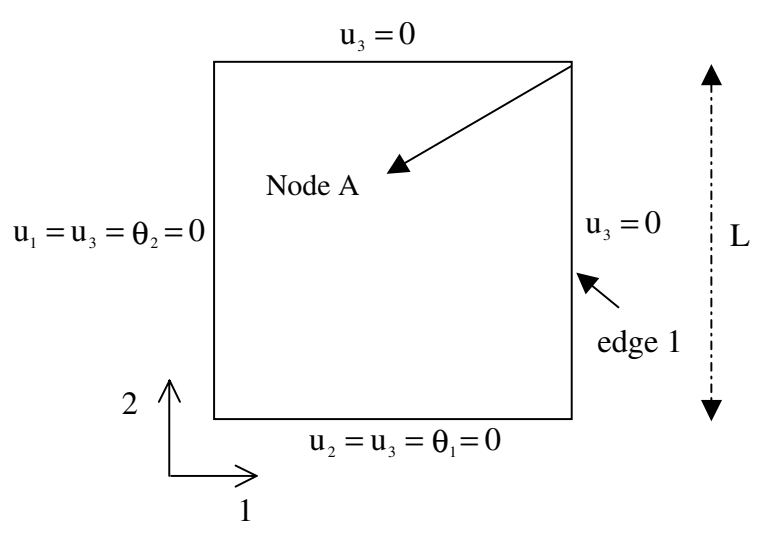

Fig. 11. Geometry and boundary conditions of the crushing test. 


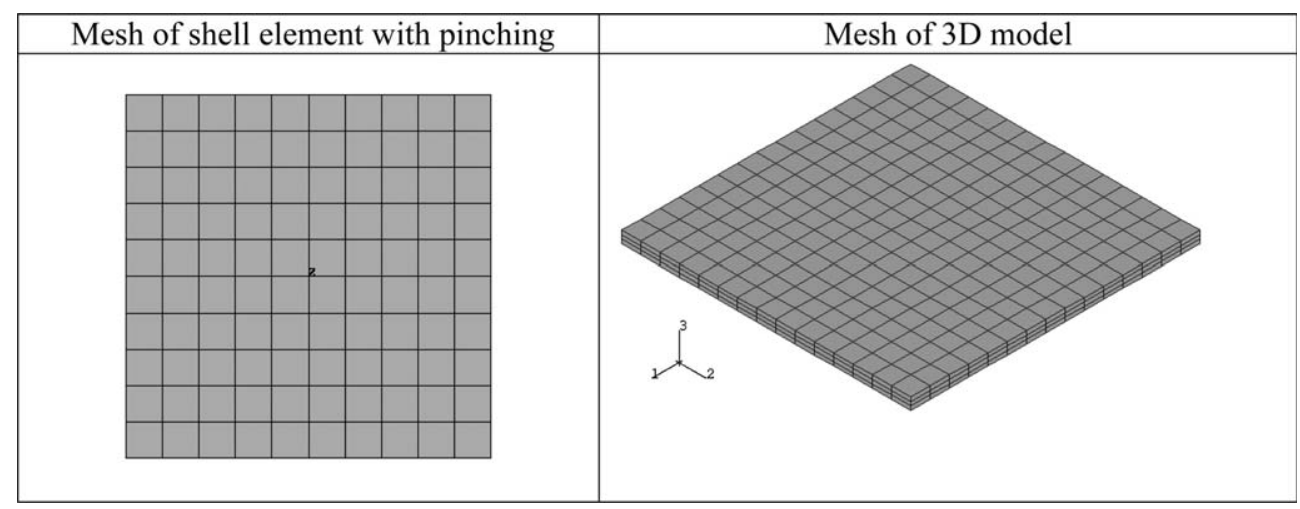

Fig. 12. Shell and three-dimensional meshes.

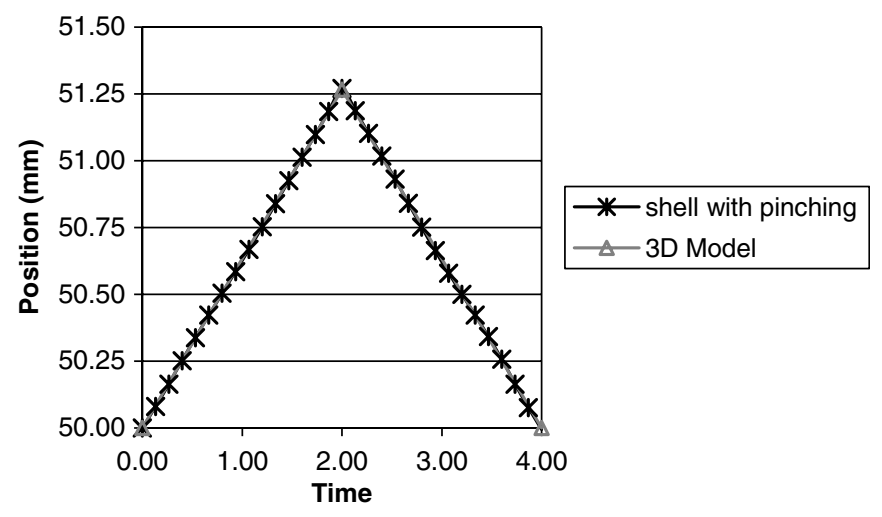

Fig. 13. $x$-component of the displacement of node $A$.

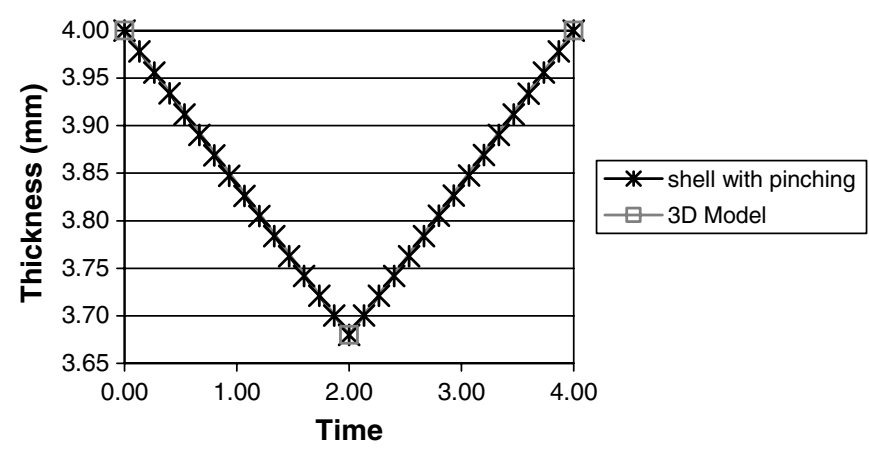

Fig. 14. Thickness evolution.

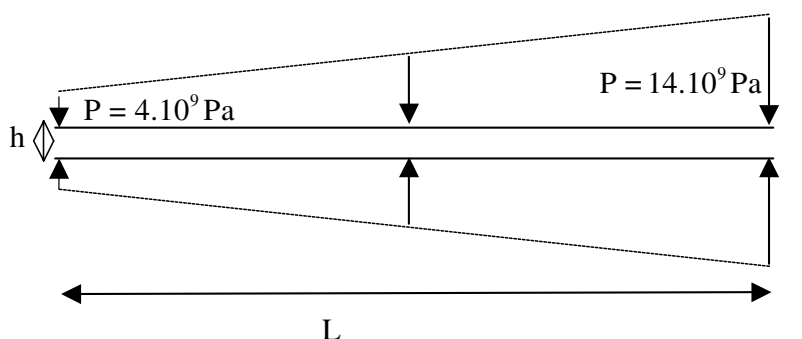

Fig. 15. Pressure along $x$.

\subsection{Traction on a square plate}

The goal of this test, is to look at the through the thickness behavior, when a membrane loading is applied. The geometry and material characteristics are identical to those given in Section 6.1 (Fig. 11). A velocity is imposed on the edge 1 (Fig. 11) of the square plate in order to have a total displacement of $8 \mathrm{~mm}$. Only a quarter of the plate is analysed. In both three-dimensional and shells model the points of the section with prescribed displacement do not move transversely, the meshes are shown in Fig. 17. The initial thickness of the plate is $4 \mathrm{~mm}$. The thickness variation obtained by the computations using the shell with pinching element, the three-dimensional model and a standard shell element are compared. In this last case, the thickness is updated from the transverse normal strain using the zero normal stress component assumption. Fig. 18 shows the thickness profile obtained along the line $y=0$. It can be seen that the membrane strain generates a strain in the thickness for the three approaches. The shell with pinching element permits to account for three-dimensional boundary conditions i.e. it is possible to prescribe through the thickness boundary conditions. It is the case for the edge with prescribed displacement of this test. The thickness is kept constant $(4 \mathrm{~mm})$ by prescribing zero transverse displacements to all the nodes of this edge. This type of boundary condition is not possible in the case of a standard shell element. The mesh has been defined as the coarser that gives a result which is not significantly modified by a refinement.

\subsection{Clamped square plate}

The objective of the following tests is to compare the results obtained with the shell element with pinching with solutions on traditional examples. These tests aim to check that the approach used in order to avoid the pinching locking (detailed in Section 5) (B1) is effective. The computations are made both for small and large displacement. This last case is necessary in forming process simulations. The comparisons are carried out between standard shell elements and the shell element with pinching. In last case 


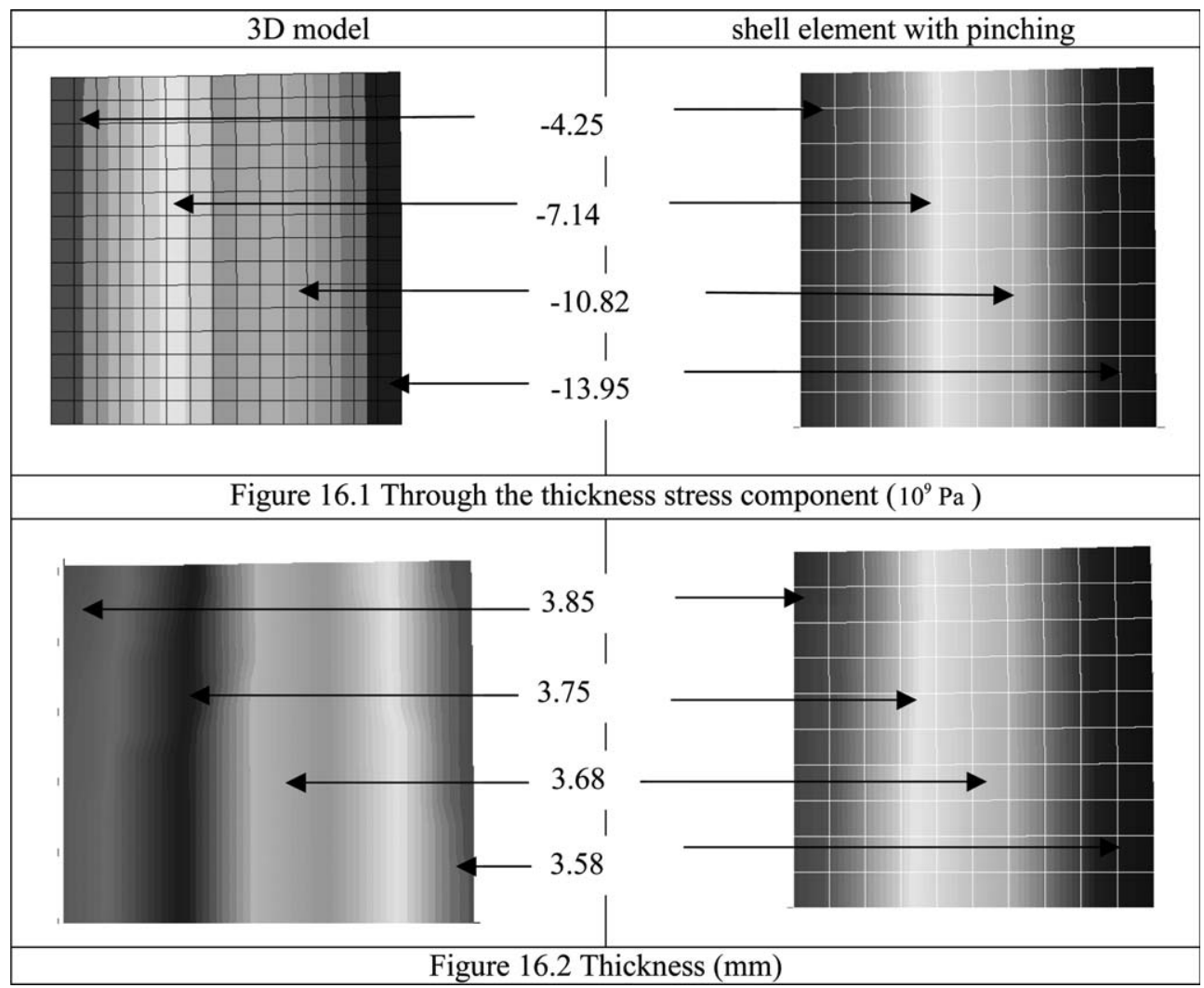

Fig. 16. Through the thickness stress (1) and thickness (2).

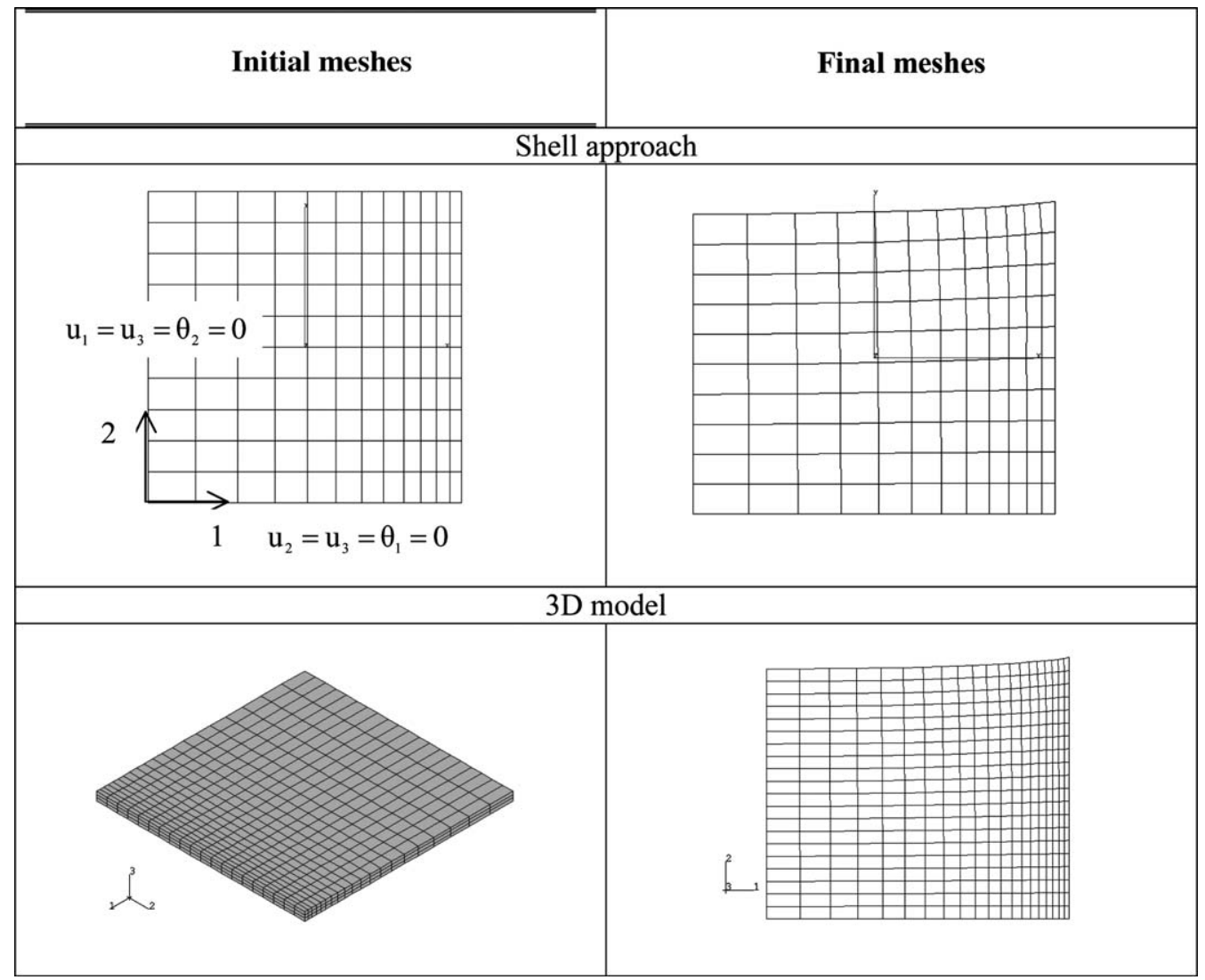

Fig. 17. Meshes used for the traction on a square plate. 


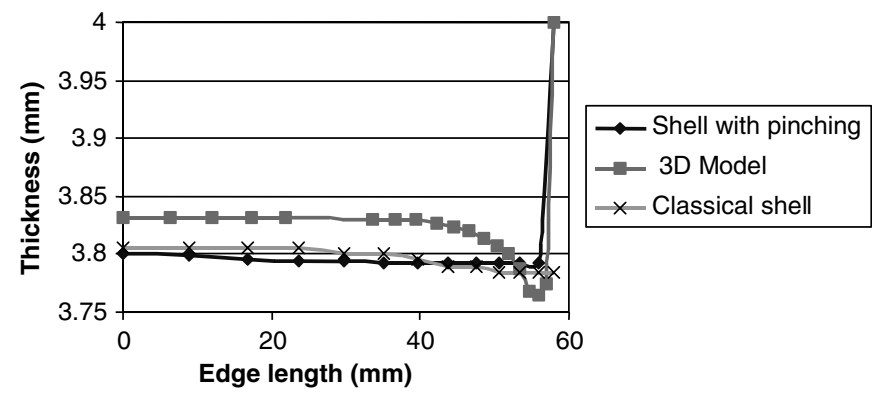

Fig. 18. Comparison of the thickness profiles.

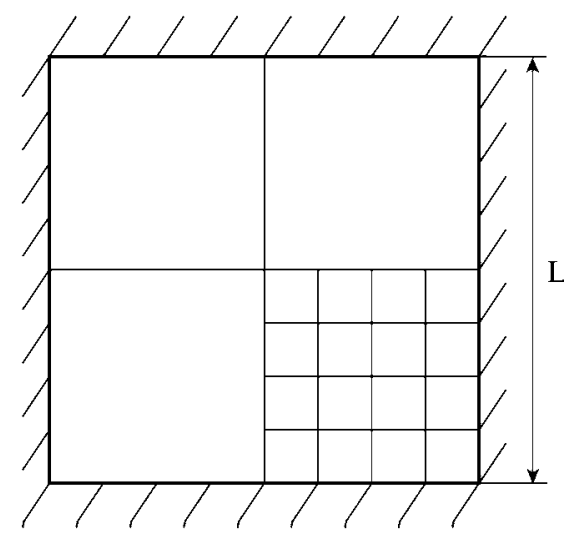

Fig. 19. Clamped square plate.

both complete three-dimensional material law and material law based on uncoupled bending and pinching (call uncoupled behaviour) are considered.

A square plate is clamped on its four sides and is subjected to an uniform transverse loading $\left(E=2 \times 10^{11} \mathrm{~Pa}\right.$; $\left.v=0.3 ; L=1 \mathrm{~m} ; h=2 \times 10^{-3} \mathrm{~m}\right)$. The computation is only made on a quarter of the plate for symmetry (Fig. 19). The deflection of the central node of the plate is equal to $2.5 \mathrm{~mm}$, for an applied pressure equal to $500 \mathrm{~Pa}$ [27]. Fig. 20 shows the transverse displacement at the center of the square plate. The computations performed with shell elements (standard and with pinching) are compared to the reference solution of Way [27]. It can be noted that the use of the uncoupled behaviour avoids the locking

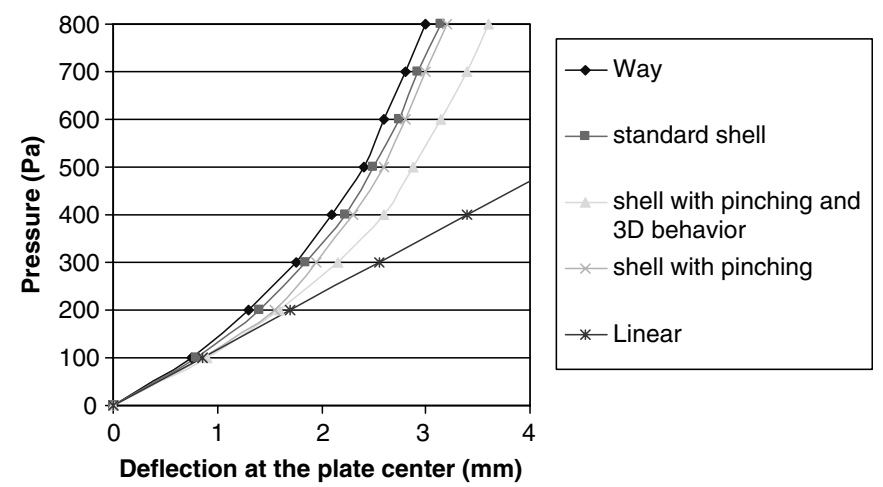

Fig. 20. Clamped square plate. Displacement at the center of the plate.

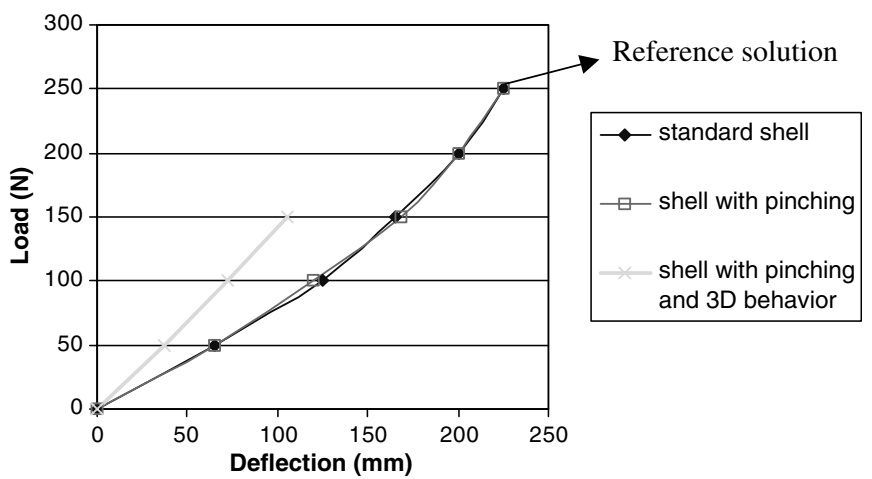

Fig. 21. Cantilever test. Large displacements of the free edge.

and leads to results that are equivalent to those obtained by standard shell elements and close to the reference solution.

\subsection{Analysis of a cantilever}

The objective of this test is to verify that the good results obtained in Section 5.2 on the cantilever plate test and especially the locking avoidance will be confirmed when the transverse displacement is large. The test is similar to that those shown in Fig. 11 with length $L=0.4 \mathrm{~m}$, width $l=0.02 \mathrm{~m}$, thickness $h=0.02 \mathrm{~m}, E=10^{9} \mathrm{~Pa}, v=0.3$. In the case of a $250 \mathrm{~N}$ concentrated, a reference solution of the deflection is given by [28] and is equal to $224 \mathrm{~mm}$.

The transverse displacements computed by the different approaches are presented in Fig. 21. For a load value equal to $250 \mathrm{~N}$ the maximum transverse displacements is in good agreement with the reference solution and with the standard shell solution if the uncoupled material law is used. At this load value the transverse displacement is larger than $L / 2$.

The elementary tests presented have first shown the ability of the presented shell element to describe through the thickness effects and especially to compute transverse stresses. They also have show the efficiency of the bendingpinching decoupling in the material law in order to avoid locking and obtain results in good adequacy with reference solutions. The final objective of the development of this element is now to use it in forming processes simulations and especially the forming and the consolidation step of the CFRTP manufacturing process described in Section 2. In this case the external load is coming from the contact between the tools and a ply or between two plies. In these analyses, the main result is the evolution of the normal stress component that will be an indicator of the reconsolidation and of porosity closing.

\section{Forming and re-consolidation stages of a part with a $Z$ section}

The forming simulation of a part described in Section 2.2 is performed. The section geometry is detailed in Fig. 22. An initially blank flat is positioned between the 


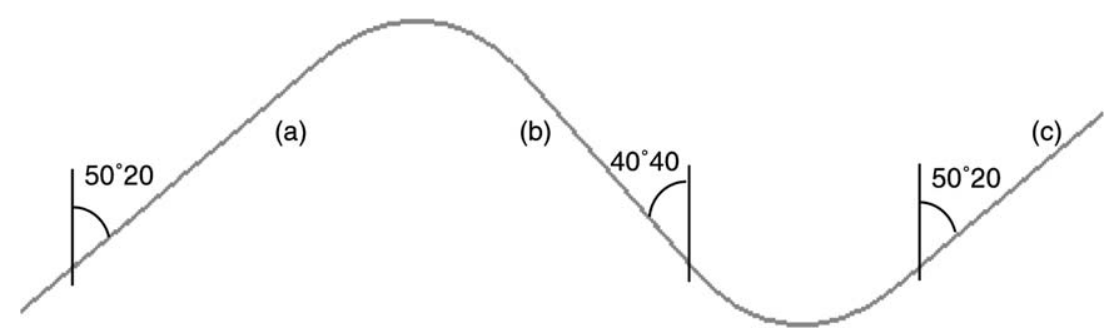

Fig. 22. Profile of the $\mathrm{Z}$ section.

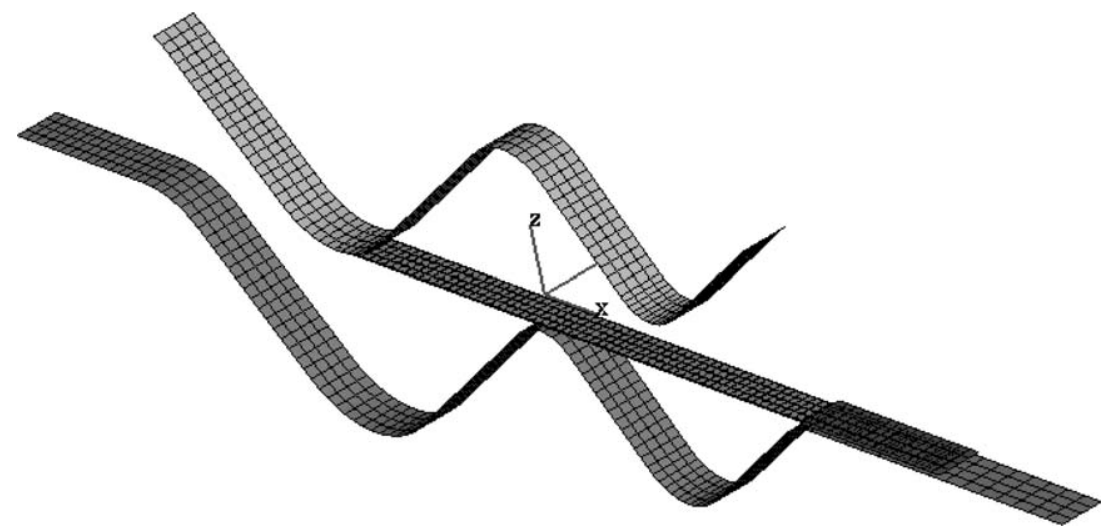

Fig. 23. Initial meshes of the part and of the tool.

punch and the die (at the forming temperature) as represented in Fig. 23. A blankholder is used is order to support the composite at the beginning of the process. It is subjected to a $8 \mathrm{kN}$ load, during all the process. The displacement of the punch is shown in Fig. 24. The distance between the punch and the die decreases to $1.35 \mathrm{~mm}$. Then, the re-consolidation stage, i.e. compression between the die and the punch, is carried out.

Fig. 25 shows the shape obtained by the simulation and through the thickness stress component in progress and at the end of the forming stage. During forming this stress component is close to zero anywhere, except in the curved parts where it is negative i.e. a compressive stress. This is in good agreement with the micrographies carried out and shown in Section 2.2. At the end of the forming, this stress

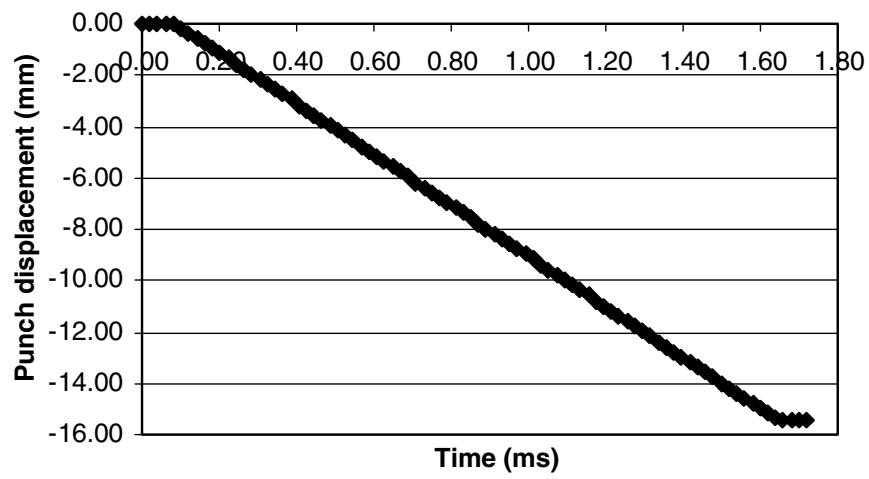

Fig. 24. Displacement of the punch during the process. component still remains close to zero in the straight parts and it is negative (compression) in the curved parts.

During the reconsolidation stage, the contact loads between the ply and the tools increase significantly (Fig. 26). The computed through the thickness stress increases (absolute value) (Fig. 27), and becomes large enough to close porosities of the straight parts in good. This is again in good adequacy with the experimental observations.

Let us note that the computed stress is less important in the more sloping part (zone b) compared to the zone a, in a coherent relationship with the angles of inclination (Fig. 22).

This shows that the computations of the through the thickness stresses permit to forecast the consolidation zones i.e. the zones where the porosities are removed. During the forming stage the transverse stresses have been found nearly equal to zero in the straight parts and significantly in compression in the curved part. That is in good agreement with the consolidation zone observed in the micrographies. In the reconsolidation stage all the transverse stresses are in compression and the porosities are removed in accordance with the experiments. Consequently, the presented finite element with transverse stress is a possible tool to analyze the consolidation during CFRTP forming process.

\section{Conclusions and perspectives}

Inter-ply porosities is one of the main feature in CFRTP forming process. Consequently it is very important to 


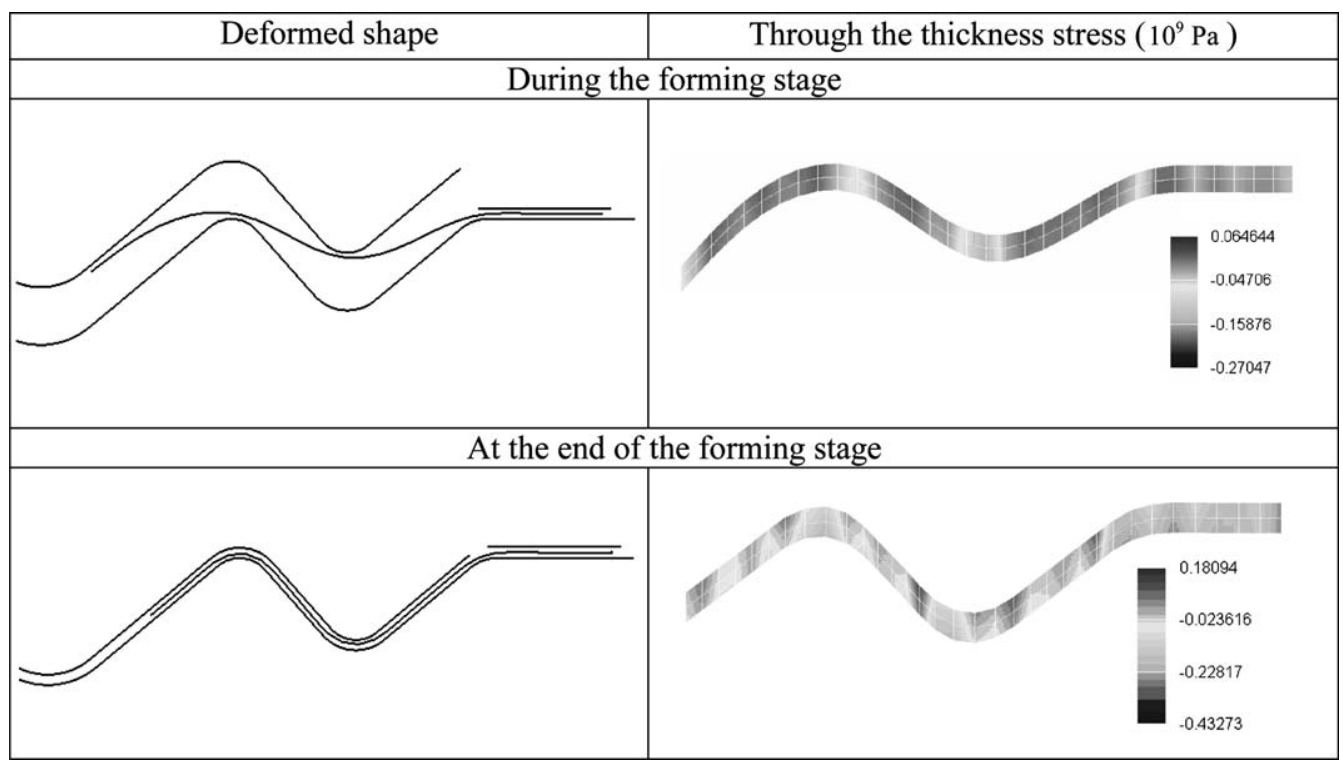

Fig. 25. Profile shape and through the thickness stress. Forming step.

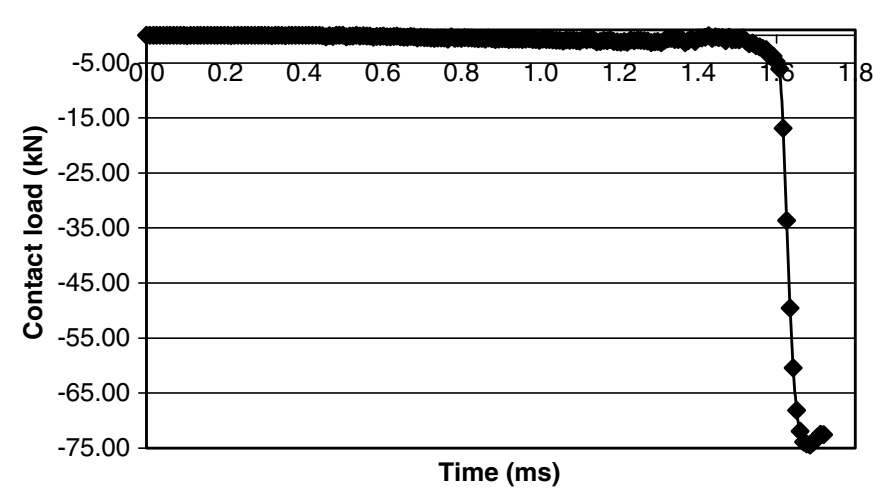

Fig. 26. Contact load during the process.

remove these porosities. This needs to apply an important enough compression especially during the reconsolidation stage. The simulation of this reconsolidation phenomenon needs to compute the through the thickness stress. In order to avoid a $3 \mathrm{D}$ computation of each ply that would not be possible in practice for a forming process, a shell finite ele- ment with transverse stress has been proposed in the present work. A supplementary degree of freedom corresponding to the through the thickness strain (assumed constant) is introduced. The approach keep the five standard shell degrees of freedom. A locking phenomenon due to the pinching has been avoid by the use of a material law where bending and pinching are uncoupled. Under this condition the element has given good results to standard tests and has permitted to determine the transverse normal stresses in the forming process of a part. The obtained transverse normal stresses are in good agreement with experimental reconsolidation (i.e. porosity removing) results.

Nevertheless the crushing used law in this work is elastic and it will be very important to use more physical laws relating $\sigma_{33}$ and $\varepsilon_{33}$. Many works in different fields have already be done on this subject $[29,30]$. It would be necessary to extend these works to the transverse mechanical behaviour of CFRTP that, of course, mainly depends of the temperature.

\begin{tabular}{|c|c|c|}
\hline During the re-consolidation step & At the end of the re-consolidation step \\
\hline \multicolumn{2}{|c|}{ Through the thickness stress $\left(10^{9} \mathrm{~Pa}\right)$} \\
\hline & -0.021377 & \\
-0.24116 & \\
-0.46094 & \\
-0.68072 & & -0.090828 \\
& & -0.42594 \\
& & -0.76104 \\
\hline
\end{tabular}

Fig. 27. Through the thickness stress. Re-consolidation stage. 


\section{Acknowledgements}

The authors acknowledge the support provided by the EADS aeronautical company and thank their correspondents Serge Maison Le Poec and Eric Soccard.

\section{References}

[1] Makinouchi A, Nakamachi E, Onate E, Wagoner RH, editors. Numisheet'93, Numerical simulation of 3-D sheet metal forming processes - verification of simulation with experiments, Japan, 1993.

[2] Stasik MC, Wagoner RH. Forming of Taylor-welded aluminium blanks. Int J Form Process 1998;1(1):9-33.

[3] Galbraith PC, Fin MI. Evaluation of an LS Dyna model for deep drawing of aluminium sheet. In: Proceedings of FE simulations of 3D sheet metal forming processes in automotive industry, Zurich, 1991.

[4] Cogswell FN, Leach DC. Thermoplastic structural composites in service. Plastic Rubber Compos Process Appl 1992;18:249-54.

[5] Stockes VK. Thermoplastics as engineering materials: the mechanics, materials, design, processing links. J Eng Mater Technol 1995; 117:448-55.

[6] Krebs J, Friedrich K. A direct comparison of matched-die versus diaphragm forming. Composites A 1998;29A:183-8.

[7] Maison S, Thibout C, Garrigues C, Garcin JL, Payen H, Sibois H, et al. Technical developments in thermoplastic composites fuselages. SAMPE J 1998;34(5):33-9.

[8] Pora J. Composite materials in the Airbus A380-from history to future. In: Proceedings of ICCM13, Plenary lecture, CD-ROM, 2001.

[9] Cheruet A. Analyse et simulation de la mise en forme des composites thermoplastiques, $\mathrm{PhD}$ thesis, University of Orléans, 2001.

[10] Cheruet A, Soulat D, Boisse P, Soccard E, Maison-le Poec S. Analysis of the interply porosities in thermoplastic composites forming processes. Int J Form Process 2002;5(2-4):247-58.

[11] Wang NM, Tang SC. Analysis of bending effects in sheet forming. Int J Numer Meth Eng 1988;25:255-67.

[12] Murtagh AM, Monaghan MR, Mallon PJ. Investigation of the interply slip process in continuous fibre thermoplastic composites. In: Proceedings of ICCM9, Madrid, Juillet, 1993.

[13] Lee W, Springer G. A model of the manufacturing process of thermoplastic matrix composites. J Compos Mater 1987;21:1017-55.

[14] Philips R, Akyuz DA, Manson JAE. Prediction of the consolidation of woven fibre reinforced thermoplastic composite: isothermal case. Composite A 1998;29A:395-402.
[15] Simo JC, Rifai MS, Fox D. On a stress resultant geometrically exact shell model. Part 4: Variable thickness shells with through-thethickness stretching. Comput Meth Appl Mech Eng 1990;72:267304.

[16] Büchter N, Ramm E, Roehl D. Three-dimensional extension of nonlinear shell formulation based on the enhanced assumed strain concept. Int J Numer Meth Eng 1994;37:2551-68.

[17] Bischoff M, Ramm E. Shear deformable shell elements for large strains and rotations. Int J Numer Meth Eng 1997;40:4427-49.

[18] Bletzinger KU, Bischoff M, Ramm E. A unified approach for shearlocking-free triangular shell finite elements. Comput Struct 2000;75:321-34.

[19] Coquery MH. Modélisation d'un joint de culasse multifeuille, PhD thesis, ENSAM, Paris, 1991.

[20] De Luca P, Lefebure P, Pickett AK. Numerical and experimental investigation of some press forming parameters of two fibre reinforced thermoplastics: APC-AS4 and PEI-CETEX. In: Fourth international conference on flow processes in composites, Aberyswyth, Wales, 1996.

[21] Belytschko T, Lin J, Tsay C. Explicit algorithms for the non linear dynamics of shells. Comput Meth Appl Mech Eng 1984;42: $225-51$.

[22] Bischoff M, Ramm E. On the physical significance of high order kinematic and static variables in a three-dimensional shell formulation. Int J Solids Struct 2000;37:6933-60.

[23] Touratier M. Maitrise des déformations à froid et à chaud dans les moteurs à combustion interne, LMSP-RENAULT Report, 2000.

[24] Polit O. Eléments finis en calcul de structures et application aux multicouches, Thesis for accreditation to supervise research, 2000.

[25] Sansour C, Buer H. An exact finite rotation shell theory, its mixed variational formulation, and its finite element implementation. Int $\mathbf{J}$ Numer Meth Eng 1992;34:73-115.

[26] Parisch H. An investigation of a finite rotation four node assumed strain shell element. Int J Numer Meth Eng 1991;31(1): $127-50$.

[27] Hughes TJR, Liu WK. Nonlinear finite element analysis. Part 1: Three dimensional shells. Comput Meth Appl Mech Eng 1981;26:331-62.

[28] Bisshopp KE, Drucker CD. Large deflections of cantilever beams. Quart Appl Math 1945;3:272.

[29] Gutowski TG. A resin flow/fibre deformation model for composites. SAMPE Quart 1985;16(4):58-64.

[30] Baoxing C, Chou TW. Compaction of woven-fabric preforms in liquid composite molding processes: single layer deformation. Compos Sci Technol 1999;59:1519-26. 